Spring 4-10-2021

\title{
Indwelling Urinary Catheter Removal HOUDINI Protocol
}

\author{
Fatima Villacruz \\ University of St. Augustine for Health Sciences, f.villacruz@usa.edu \\ DOI: https://doi.org/10.46409/sr.VIQS5210
}

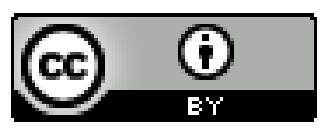

This work is licensed under a Creative Commons Attribution 4.0 License.

Follow this and additional works at: https://soar.usa.edu/scholprojects

Part of the Other Nursing Commons, and the Urology Commons

\section{Recommended Citation}

Villacruz, F. (2021). Indwelling Urinary Catheter Removal HOUDINI Protocol. [Doctoral project, University of St Augustine for Health Sciences]. SOAR @ USA: Student Scholarly Projects Collection. https://doi.org/ 10.46409/sr.VIQS5210

This Scholarly Project is brought to you for free and open access by the Student Research at SOAR @ USA. It has been accepted for inclusion in Student Scholarly Projects by an authorized administrator of SOAR @ USA. For more information, please contact soar@usa.edu, erobinson@usa.edu. 


\title{
Indwelling Urinary Catheter Removal HOUDINI Protocol
}

\author{
Fatima Villacruz, MBA, MSN, RN \\ School of Nursing, University of St. Augustine for Health Sciences \\ This Manuscript Partially Fulfills the Requirements for the \\ Doctor of Nursing Program and is Approved by: \\ Sue Bingham, $\mathrm{PhD}, \mathrm{RN}$ \\ Joseph Tadeo, DNP, MPH, RN, CNS
}

April 8, 2021 


\begin{abstract}
Practice Problem: Catheter-associated urinary tract infections (CAUTIs) in spinal cord injury (SCI) patients have many negative health consequences, including increased cost, increased length of hospital stays, delay in bladder training, increased associated infections, and mortality. PICOT: The PICOT question that guided this project was: In adult SCI patients (P), does the implementation of a nurse-driven indwelling urinary catheter removal protocol (I), compared to without a nurse-driven protocol $(\mathrm{C})$, decrease the indwelling urinary catheter days and the occurrence of CAUTIs $(\mathrm{O})$ within six weeks $(\mathrm{T})$ ?

Evidence: Nurse-driven discontinuation protocols are an effective method of decreasing indwelling urinary catheter (IUC) days and CAUTI rates. Each day a catheter remains in place, the risk of CAUTI increases.
\end{abstract}

Intervention: The registered nurses used the Indwelling Urinary Catheter Removal (IUCR) HOUDINI nurse-driven protocol to assess whether patients met the criteria to have their indwelling urinary catheter (IUC) removed and bladder training initiated.

Outcome: Pre-and post-implementation data for IUC days and CAUTI rates were evaluated using descriptive statistics. Catheter days did not decrease in the post-intervention; however, there was earlier catheter removal and zero occurrences of CAUTIs in the post-intervention group.

Conclusion: Implementation of the evidence-based nurse-driven protocol IUCR-HOUDINI in the SCI unit promoted earlier catheter removal, improved patient outcomes related to CAUTIs, and empowered nurses to manage a patient's IUC more effectively. 


\section{Indwelling Urinary Catheter Removal HOUDINI Protocol}

Patients with a spinal cord injury (SCI) are at a higher risk of developing urinary tract infections (UTIs) (Salameh et al., 2015). UTIs are the most common cause of emergency department visits, hospital readmission, and the second leading cause of death (Cardenas et al., 2004). When a SCI patient develops a UTI during acute care admission, it lengthens the hospital stay and may delay the transfer to a rehabilitation center. In rehabilitation, the development of a UTI often results in readmission to the hospital. These interruptions and impediments lower patient self-esteem, distract involvement in recovery, place a demand on hospital bed capacity, and extend the patient's hospital stay (Hennessey et al., 2018).

The literature has shown that neurogenic bladder dysfunction and poor bladder management can increase UTI risk (Roth et al., 2019). Selecting a method that minimizes bladder foreign bodies yet emptying the bladder efficiently is paramount in reducing UTI risk (Underwood, 2015). As healthcare professionals, nurses are committed to implementing evidence-based (EB) strategies that can help avoid the risk of harming the patients while adhering to the principle of nonmaleficence. This project's primary objective was to examine the positive effect of a nurse-driven urinary catheter management protocol to reduce the number of IUC days and the occurrence of catheter-associated urinary tract infection (CAUTI) rates among SCI patients.

\section{Significance of the Practice Problem}

The Centers for Disease Control and Prevention (CDC) in 2018 reported UTIs as the fourth most common healthcare-associated infection (HAI). UTIs are linked with increased morbidity and mortality, prolonged hospital stays, increased hospital costs, and compromised_patient safety (Rahimi et al., 2019). In 2015, the CDC reported that 75\% of UTIs 
were associated with IUCs (CDC, 2015). An average of $25 \%$ of hospitalized patients are catheterized during admission; therefore, practices and protocols must be in place to minimize infection risk (Dy, 2016). It is estimated that approximately 1.7 million patients in the United States are affected by HAIs each year. Therefore, the reduction of HAIs continues to be a national patient safety goal (Joint Commission, 2015).

Globally, prevalence of UTIs range between $25 \%$ and $40 \%$ among patients, and accounts for over six million patient visits to medical providers annually (Rahimi et al., 2019). Roth et al. (2019) declared that all patients who had a catheter for more than six days, aged 60 and above, should be checked for UTI symptoms. Data from the National Healthcare System Network ([NHSN], 2015) indicated that acute care hospitals in 2009 showed CAUTI rates of 3.1 to 7.5 infections per 1000 catheter-days. CAUTIs place a total financial burden of \$340 million annually in the United States (NHSN, 2015).

UTI is a premier benchmark outcome measured by the Center for Medicaid and Medicare Service (CMS), which is no longer reimbursing for treatment if a patient acquires a UTI during hospitalization (CMS, 2017). Roth et al. (2019) emphasized that IUCs are the frequently used urethral devices associated with complexities, such as UTIs and trauma. Given IUC impediments and high utilization in healthcare, the potential for liability risk is evident. Awal et al. (2016) affirmed that severe complications and even mortality from urosepsis became a healthcare liability, and resultant claims usually resulted in compensation favoring the plaintiff. The medical interventions and treatments for CAUTIs elevate healthcare costs.

The financial cost for diagnosed CAUTI is estimated at up to $\$ 2,700$ per case (Gesmundo, 2016). Nurses have an ethical duty to improve health, prevent risks, and alleviate suffering (CDC, 2015). However, despite the availability of procedures and standards to prevent 
CAUTIs, the infection rates have not been reduced and are the predominant medical condition in the acute care setting.

\section{PICOT Question}

The PICOT question that directed a literature search for this Doctorate in Nursing Practice (DNP) project was: In adult SCI patients (P), does the implementation of a nurse-driven indwelling urinary catheter removal protocol (I), compared to without a nurse-driven protocol (C), decrease the indwelling urinary catheter days and the occurrence of CAUTIs $(\mathrm{O})$ within six weeks (T)?

The target participants selected for this evidence-based (EB) project were the adult SCI patients admitted to the acute SCI rehabilitation unit during the time frame of the six-week project implementation. All eligible participants were female or male between the ages of 18 to 65 years old with IUC. Since these identified participants were admitted with neurogenic bladder dysfunction due to SCI, they are high-risk of acquiring CAUTI due to the IUCs. The most common complications of the neurogenic bladder due to SCI are UTI, urinary stones, and renal impairment (Ong et al., 2020). These complications are associated with the pathology of bladder dysfunction or occur due to the application of IUCs for drainage.

The literature revealed that when IUCs were utilized for long-term bladder drainage in patients with SCI, the risk for asymptomatic bacteriuria and UTIs could be increased (Salameh et al., 2015). Hence, having an accessible, EB nurse-driven protocol to remove an IUC empowers the nurses at the bedside. These protocols enhance patient safety, increase staff satisfaction, and promote efficiency in care delivery (Mori, 2014; Scanlon et al., 2017; Timmons et al., 2017). Also, it permits nurses to practice autonomously to identify, assess, and remove an IUC (Dy, 2016). 
Currently, the project manager works in a facility without a nurse-driven protocol to guide the nurses in managing the IUC removal. Instead, in the current practice, when an SCI patient is admitted with an IUC, the nurses are expected to wait for the primary physician to order the discontinuation of the IUC. This expectation of practice contributed to the delay of any bladder training initiation. These deferrals in IUC removal can potentially cause CAUTI occurrence for patients in the SCI unit. The EB project's objective was to determine the efficacy of nurse-driven protocol for IUC removal in preventing CAUTI and decreasing the total number of IUC days in the SCI patients compared to not having a nurse-driven protocol six weeks of the project implementation.

\section{Evidence-Based Framework and Change Theory}

The EB model selected to be used for this change project was the Iowa Model of Evidence-Based Practice (EBP). This framework supports the promotion of healthcare quality and positive clinical outcomes. Using the Iowa Model enhances healthcare excellence because it is identified as an exemplary model for recognizing the problem and assessing evidence to create a practice change (Buckwalter et al., 2017). The authors of Iowa Model recommended that healthcare workers address questions such as how nurses can transform clinical practice at the bedside or how the nurses can utilize the latest clinical evidence to improve care for the patients. Currently, EB pathways are driven by many sources, such as clinical examination, observational work, outcome investigation, and case analysis. The Iowa Model plays a crucial role in providing the platform necessary for organizations to improve patient outcomes. It also helps the nurses at the bedside to enhance comprehension of decreasing the occurrence of CAUTI. Translating knowledge into practice and understanding indications to implement new standards is a 
significant step towards compliance with the EB recommendations for the management of IUCs (Doody \& Doody, 2011).

The Iowa Model of EBP consists of several steps that drive an examination of current practice and promote relevant findings to improve patient outcomes (Melnyk \& Fineout-

Overholt, 2011). The systematic process includes (1) identifying a topic or problem, (2) creating a team, (3) collecting relevant evidence and literature, (4) critiquing the literature, (5) synthesizing a practice standard, (6) implementing the change, and (7) evaluating the practice change.

Any change in clinical practice is not always easily and readily accepted at the bedside. Besides the Iowa Model, Lewin's theory of change was utilized as a framework to implement the EB project. Lewin's theory revolves around the three key concepts: (1) unfreezing, (2) moving, and (3) refreezing (Mitchell, 2013). Unfreezing is the process that includes finding the means of encouraging people to let go of an old pattern of behavior that may not be working well. Unfreezing is necessary to overcome the strain of individual resistance and group conformity. The moving phase comprises changing perceptions, feelings, and behaviors to more productive functioning. Finally, once the necessary change has occurred, the refreezing stage can be adjusted to measure change sustainability and overall success of the practice change. The new change is integrated and supported by rewarding the outcomes of change behavior demonstrated by bedside nurses.

\section{Evidence Search Strategy}

The literature review was conducted applying the PICOT statement to have a firm understanding of how a nurse-driven protocol can decrease IUC days and CAUTIs. The University of St. Augustine's electronic resource databases were accessed to review scholarly 
articles relevant to the EB project. Initial database searches included: PubMed, Joanna Briggs

Institute, and Cumulative Index to Nursing and Allied Health Literature (CINAHL) Complete.

The specific keywords used in the literature search were nurse-driven protocol and CAUTI prevention employing the advanced search key options. The inclusion criteria included articles written in the English language, published within the last six years, full-text, and academic peerreviewed journals. Furthermore, the exclusion criteria were applied, which included articles that focused on pediatrics, or had outpatient and long-term care for settings. The entire process and search strategy of evidence were instrumental in finding relevant articles applicable to the project.

\section{Evidence Search Results and Evaluation}

The evidence search results and evaluation of the literature were conducive to the IUC nurse-driven protocol project. These kinds of literature would be vital to the chosen project because it provided reliable evidence to support the PICOT question. One thousand nine hundred twenty-five articles were scanned for eligibility, but only ten were identified for inclusion, as illustrated by the PRISMA chart (see Appendix A). All ten articles were appraised to examine the IUC removal nurse-driven protocol and outcomes. Each article supported the implications of clinical practices at the bedside regarding the IUC removal protocol to reduce catheter days and CAUTI occurrences. The Rapid Critical Appraisal of Evidence-based Practice Implementation by Melnyk and Fineout-Overholt (2015) was utilized to appraise the chosen articles' level of evidence. The level of evidence of all the articles synthesized ranges from Level II through IV. The synthesized articles' findings offered valuable support for the use of IUC removal nursedriven protocol in reducing IUC days and CAUTI rates. 


\section{Themes from the Evidence}

A synthesis of the literature was applied to understand the PICOT question components better. This synthesis was comprised of ten articles: four quantitative (Mori, 2014; Scanlon et al., 2017; Timmons et al., 2017; Underwood, 2015), one qualitative (Maxwell et al., 2018), one descriptive (Olson-Sitki et al., 2015), one interventional (Johnson et al., 2016), one quasiexperimental (Zurmehly, 2018), one retrospective (Ballard et al., 2018), and one systematic review (Durant, 2017). A summary of primary articles reviewed can be found in Appendix B, and a systematic review is shown in Appendix C. The evidence concepts were collected meritoriously, concluding nurse-driven protocol, IUC reduction, and urinary tract infection as the main themes.

\section{Nurse-Driven Protocol}

The nurse-driven protocols dictate the need to reduce the IUC usage by its early discontinuation (Johnson et al., 2016; Mori, 2014; Timmons et al., 2017; Zurmehly, 2018). One identified risk factor for CAUTIs is the prolonged use of IUC (Timmons et al., 2017; Underwood, 2015). The CDC (2018) recommended that the discontinuation of IUC should be done when it is no longer needed, and it should be used for specific indications only. The IUC usage in acute care hospitals is noted to not be adequately managed. However, the evidence supports that a decrease in IUC application can play a crucial role in reducing CAUTIs in acute care facilities (Durant, 2017).

Mori (2014) confirmed a nurse-driven IUC protocol in an acute care facility can reduce the prevalence of IUCs, dwell times, and infection rates. The protocol outcomes exhibited a prevalence of IUC days, and the incidence of CAUTIs decreased from pre-implementation to post-implementation of the protocol. This protocol has shown to reduce IUC incidence and dwell 
times; thus, enhancing patient outcomes (Maxwell et al., 2018; Mori, 2014). The investigation results displayed a reduction in dwell time from 1,280 days pre-implementation to 1,025 days post-implementation, a decreased use of catheters from $37.6 \%$ to $27.7 \%$, including a reduction in CAUTIs from $0.77 \%$ to $0.35 \%$ (Mori, 2014).

Timmons et al. (2017) implemented a CAUTI prevention, which incorporated a nursedriven protocol in a 30-bed adult neurological intensive care unit. This intervention involved comprehensive staff education, which included daily reinforcement, an online model, and the use of simulation. Experts measured the catheter utilization, CAUTI rates, length of stay (LOS), and cost associated with CAUTI. The nurse-driven protocol led to an average day of $2.5 \%$, the CAUTI rate decreased by $20.5 \%$, and cost savings of $40.7 \%$ (Timmons, Vess \& Conner, 2017).

\section{Indwelling Catheter Reduction}

Each day an IUC remains in place, the risk of a patient acquiring a UTI increases. Therefore, the nurses' ongoing patient need assessment should be performed at a minimum of 24 hours (AHRQ, 2015; Durant, 2017). The IUC should be discontinued if not indicated (AHRQ; 2015; Durant, 2017). One approach identified to address this challenging clinical practice is for the nurses to adopt a nurse-driven IUC removal protocol. This effort empowered nurses to discontinue IUC if they do not meet the appropriate usage criteria (AHRQ, 2015).

Underwood (2015) examined the IUC utilization and CAUTI rate after using a nursedriven IUC removal protocol. The nurse-driven protocol confirmed using various interventions such as catheter care and maintenance, early catheter removal, and improved urine collection methods can reduce catheter utilization and CAUTI rates. IUCs are typically used for convenience, which can be avoided by nurses performing daily assessments and removing the IUC if not indicated (Ballard et al., 2018; Olson-Sitki et al., 2015). It is also essential to ensure 
that the nurses at the bedside carry out the catheter care guidelines correctly to decrease preventable complications, such as CAUTIs (Durant, 2017; Johnson et al., 2015).

The development of nurse-driven protocol aims to reduce the use of IUCs, which will decrease CAUTI rates, associated cost, and LOS in the acute care setting (Timmons et al., 2017; Underwood, 2015). Efficient ways to avoid continuous utilization include staff education, nursedriven protocols, automatic stop orders, and instituting healthcare provider reminders (Ballard et al., 2018; Johnson et al., 2015). The evidence presented in the literature strongly supported that implementing a nurse-driven protocol will decrease IUC days and reduce CAUTIs.

\section{Urinary Tract Infections}

UTIs are known as one of the most prevalent HAIs, and CAUTIs account for approximately $75 \%$ of all UTIs (CDC, 2015). CAUTIs are the leading cause of avoidable HAIs in the United States (ANA, 2017; CDC, 2015). UTIs can develop when a patient has IUC for more than two days (CDC, 2015). The use of IUCs portrays the correct mode of treatment for many hospitalized patients; however, IUCs are not indicated for many patient conditions posing avoidable clinical harm for patients (Scanlon et al., 2017; Underwood, 2015).

\section{Practice Recommendations}

The leading cause of UTIs in an acute care environment is the use of an IUC (Ballard et al., 2018; Durant, 2017; Olson-Sitki et al., 2015). CAUTI has a significant impact on morbidity, mortality, and healthcare expenses, but it can be prevented to a great extent. The analyzed articles revealed that the high-risk determinants in developing a CAUTI were the insertion and continuation of an IUC. The literature indicated that executing measures for the need of the insertion and interventions to reduce the catheter days can decrease CAUTI incidence (Johnson et al., 2016; Mori, 2014; Underwood, 2015). These interventions included specific standing 
protocols for insertion, needing a physician order, a nurse-driven protocol for timely removal, and automatic stop orders (Ballard et al., 2018; Underwood, 2015; Zurmehly, 2018). All these measures enhance awareness of the need for and the presence of the catheter. However, all these approaches need reinforcement from the frontline staff to intervene when IUC should be removed appropriately.

A culture change was necessary to implement the urinary management nurse-driven protocol. It was also imperative to have open communication and strong collaboration among the interdisciplinary team, specifically between physicians and nurses, to effectively execute the urinary management nurse-driven protocol intervention and sustain the project once implemented. Based on the evidence examined, the recommendation for a practice change supported using the evidence-based nurse-driven protocol to reduce CAUTIs and improve patient safety and promote quality care. Additionally, implementing an EB guideline to reduce CAUTIs aids in bridging the gap in clinical practice, including offering increased knowledge at the bedside for significant prevention of CAUTI incidence (Durant, 2017; Underwood, 2015).

\section{Project Setting}

The EB improvement project setting was a public hospital with 175 beds in Southern California. The facility handles approximately 3,000 admissions annually and is supported by medical-surgical and rehabilitation services. There are four specialty rehabilitation units: brain injury, pediatric, stroke, and spinal cord injury services. Furthermore, it also provides a comprehensive outpatient program that offers over 50,000 visits annually, including outpatient therapy and lifetime specialty care for persons with disabilities (dhs.lacounty.gov). The IUCRHOUDINI protocol project was implemented in a 25-bed SCI acute rehabilitation unit. 


\section{Organizational Structure}

Implementing the EBP, the focus was on reducing the number of IUC days and CAUTI occurrences among the SCI patients. The application of an organizational assessment tool was essential for implementing and guiding the project. The tool utilized for this project to determine the organization's readiness to adopt the change was the Checklist to Assist Organizational Readiness (CARI). The checklist was designed to support the pre-implementation, deliberation, and progress of the EBP (Barwicjk, 2011). Appraising the organizational readiness to embrace the change project by introducing the IUCR-HOUDINI nurse-driven protocol indicated that the organization had a solid senior leadership engagement that fully supported the implementation of this targeted change in practice.

Organizational readiness for change is a multi-level concept (Shea et al., 2014). Strategies that improve organizational change readiness include the active involvement of executives, unit managers, and staff. The strategic plan incorporated the executive level to guide the continuous change adaptation, organization flexibility, and acceptance of the targeted change. It was essential to develop an atmosphere of trust, which influenced positive attitudes toward organizational change (Silver et al., 2016). At the unit manager level, high readiness promoted change implementation by addressing an organization's specific needs. More particularly, at this level, change interventions emphasized open communication about the driving change factors. It was pivotal to inform the staff of how their responsibilities could be modified before, during, and after the change implementation (Aarons et al., 2015).

At the staff level, readiness was a flexible trait, and improved through employee's training and development programs (Silver et al., 2016). The organizational assessment and culture concept motivated the project manager to identify early on who would be the vital 
instrumental stakeholders who could support the project for successful implementation and sustainability. These stakeholders identified include the unit champions, frontline staff, nurse manager, clinical educator, clinical nursing director, rehabilitation clinical nurse specialist, physicians, infection control preventionist nurse, physical therapist, occupational therapist, and patients.

The occurrence that triggered the project selection was identified during the interdisciplinary rounds in the SCI unit. In the second quarter of this year, in June, seven out of fourteen patients were admitted to the acute rehabilitation SCI unit with an IUCs. During the same month of June, there was a total of 48 urinary catheter days, and one of the patients acquired a CAUTI. This finding was not a norm from the acute rehabilitation SCI service, so the team recognized that a change of practice to decrease the patient's number of IUC days and the provision for immediate IUC removal was significantly necessary. A patient's continuous usage of an IUC can pose a significant risk for developing CAUTI (Johnson et al., 2016; Mori, 2014; Underwood, 2015).

Consequently, CAUTIs can induce prolonged hospital stays, compromise patients' safety, and become a financial burden on the organization (CMS, 2017). Currently, there is no nursedriven protocol related to IUC removal that is being used in the SCI unit. Therefore, initiating an EB project on IUCR-HOUDINI protocol was an imperative action for this targeted unit. This project offered the essential benefits of improving SCI patients' bladder management and enhancing patient outcomes, including elevating the nursing practice at the bedside.

\section{SWOT Analysis}

A strengths, weaknesses, opportunities, and threats (SWOT) analysis helped determine readiness for implementing this project, as presented in Appendix D. The SWOT analysis is used 
to evaluate internal and external attributes and threats to the phenomenon of interest (Moran et al., 2020). The focus of the assessment was on evaluating an IUCR-HOUDINI protocol. The organizational assessment revealed strengths of administration support, organizational readiness for change, and sustainable change. When hospital leadership was initially involved with the project, it showed that patient outcomes are a shared team responsibility.

On the other hand, the organization exhibited weaknesses centered on lack of buy-in from staff to change; this may contribute to patient increased LOS, therefore causing a financial burden to the organization. The opportunities identified include decreased IUC use, reduced CAUTIs, improved patient outcomes, and increased patient satisfaction. If patients' experienced improved outcomes, they were satisfied with their care and would likely return for additional services. The perceived external threats recognized would be implementing the new protocol, learning curve, and financial reimbursement tied to CMS. The hospital is no longer incentivized but mandated to have decreased HAIs, which include CAUTIs.

\section{Project Overview}

The EB project aimed to implement the IUCR-HOUDINI nurse-driven protocol on an acute SCI rehabilitation unit. The implementation of the EB project covered six weeks. The project addressed the nurse's current clinical practice of handling a high volume of patients admitted with IUCs. The IUCR-HOUDINI primary intervention focused on early discontinuation of the patient's IUC upon admission to the SCI unit. The protocol aimed to reduce the IUCs days and decrease the occurrence of CAUTI in the SCI patient. After a comprehensive analysis of evidence, it was identified that IUCR-HOUDINI protocol was the best approach to implement to improve outcomes and optimize patient care. The IUCR-HOUDINI protocol was an algorithm that assisted and guided the nursing staff in determining the initial and ongoing need of the 
patient to have the IUC. The HOUDINI acronym stands for the following: H- gross hematuria;

O- urinary obstruction; U- urologic surgery; D- decubitus ulcer; I- intake and output for hourly management of hemodynamic instability; N- No code, comfort care, hospice; I-immobility due to physical constraints (Ballard et al., 2018; BJC Healthcare, 2013; Yatim et al., 2016) (see Appendix E).

The employment of the IUCR-HOUDINI protocol started upon the patient's admission. The registered nurse assessed the patient who had an IUC in place by using the "Urinary Catheter Removal Assessment Tool" (UCRAT) (see Appendix F). The UCRAT was used to identify if the patient met any of the HOUDINI criteria. If the assessment showed that the patient did not exhibit any of the HOUDINI criteria, the nurse removed the IUC and started bladder training, according to the IUCR-HOUDINI nurse-driven protocol. However, if the nurse's assessment exhibited that the patient had any of the HOUDINI criteria, the patient's IUC would not be removed by the nurse. Instead, the nurse would collaborate with the physician and continue to monitor the patient daily. It was essential to consistently reinforce the nurses by the unit champions and the project manager about the significance of utilizing the UCRAT, while the patient's IUC remains in place.

Once these clinical nursing interventions were consistently done, the SCI unit was able to proactively capture and initiate the removal of IUCs promptly, preventing CAUTI and decreasing the number of IUC days of the SCI patients. The project manager continued to collaborate with the interdisciplinary team and unit champions to validate the efficacy of the implemented protocol. The project manager maintained support among the stakeholders by meeting with the interdisciplinary team, discussing the problem identified, defining the aim of the project, and highlighting the expected patient outcome. Solicited feedback from the team was 
obtained and incorporated throughout the construction and implementation of the project.

\section{Project Mission and Vision}

The project's mission was to provide an EB intervention specific to reducing the IUC days and CAUTI occurrences in SCI patients. The vision was to empower nurses in utilizing the EB IUCR-HOUDINI protocol in removing the IUC of SCI patients appropriately and in a timely manner according to the established protocol criteria, to decrease the number of IUC days and CAUTI occurrences. Implementing the IUCR- HOUDINI protocol aligned with the organization's mission and vision, which have a primary focus of restoring health, rebuilding, and revitalizing hope for people with a life-changing illness, injury, or disability.

\section{Project Objectives}

\section{Short-term}

The first objective was to examine the latest EBP of IUCR-HOUDINI nurse-driven protocol for a patient with SCI during June before the project implementation. Next was developing the workflow of how the IUCR-HOUDINI protocol would be implemented in the target unit based on the gathered evidence, consulting, and collaborating with the certified clinical nurse specialist (CNS) assigned in the rehabilitation units. The interdisciplinary team highly respects the CNS's role and is seen as a subject matter expert in clinical nursing practice at the bedside. It also involved asking for input from the interdisciplinary team a month before the project was implemented in the selected unit. It was followed by collaborating with the infection control preventionist in gathering the pre-implementation data specific to the occurrence of CAUTI in the target unit. The project manager reviewed and examined the total occurrence of CAUTI in the SCI unit during June to determine the efficacy of the project implementation. The prime objective was to decrease the occurrence of CAUTI and the number of IUC days within 
six weeks of the project's implementation. It was vital to include the data mentioned above to measure the project's post-implementation effectiveness, as evidenced by decreased catheter days and CAUTIs when compared to the baseline data.

\section{Long-term}

The first aim was to sustain the IUCR-HOUDINI nurse-driven protocol utilization at the bedside and incorporate the registered nurses' unit-based orientation protocol once the project was implemented in the acute SCI rehabilitation unit. The second objective was to extend the implementation of the EB IUCR-HOUDINI throughout the inpatient areas after six weeks of project completion in the SCI rehabilitation unit.

\section{Risk}

Conducting a risk assessment was vital to identify the elements that could influence the interdisciplinary team's delay or failure to follow the project's projected milestone. The risk and identified unintended consequences of implementing the EB project included the patients' confidentiality, lack of staff participation, and commitment to the project. Mitigation of patient confidentiality was performed by having the utilized protected health information and data aggregated and de-identified. The lack of staff participation and commitment was mitigated by continuous open communication of reinforcing staff's compliance. It also included the project manager's consistent ability to practice active listening and seek feedback with the team while accepting constructive criticism with sensitivity and gratitude.

\section{Project Plan}

The Iowa Model of EBP was selected in planning the project because it delivers a stepby-step process of introducing and executing the change project. The first step in the Iowa Model was to determine a priority topic (Titler et al., 2001). During the interdisciplinary rounds in the 
SCI acute rehabilitation unit, the team recognized an unexpected increase in patients admitted with an IUC. It was evident that during the second quarter of June 2020, the SCI unit had seven out of fourteen patients admitted with an IUC, which also accounted for a total of 48 IUC days per month, and one of these patients acquired a CAUTI. This finding was not a norm for the acute rehabilitation SCI service. The team recognized that a change of practice to reduce the patient's number of IUC days and immediate catheter removal was necessary. It was a crucial problem that was considered a top priority, because if the issue was not addressed, hospitalacquired CAUTI was likely to become a primary adverse outcome.

The next step in the Iowa Model was to form a team. The project manager successfully created a dynamic team involved in developing, implementing, and evaluating the selected project. The team was comprised of the DNP student project manager, frontline nurses, unit nurse manager, unit educator, assistant nurse manager, physicians, rehabilitation clinical nurse specialist, infection control preventionist nurse, and the other interdisciplinary team members. Once the team's construction was finalized, the third step was searching for current literature and collecting the most relevant evidence. The searched evidence converged on the benefit of decreasing the IUC days and finding EB elements that could help illuminate how to prevent and reduce the occurrence of CAUTI for the SCI patients in the acute rehabilitation SCI unit. This effort was made by using the University of St. Augustine electronic resources databases. These databases included PubMed, Joanna Briggs Institute, and Cumulative Index to Nursing and Allied Health Literature (CINAHL) Complete. Through the search process, the project manager obtained ten high-level research articles that supported the project scheme.

The fourth step of the Iowa Model comprised the need for critiquing and synthesizing the searched evidence. The articles gathered were analyzed to facilitate a strong argument for 
implementing the EB interventions to decrease IUC days and CAUTI occurrences through the guidance of Melnyk's Hierarchy Levels of Evidence. Through the conceptual application of Melnyk's Hierarchy Levels of Evidence, a complete examination of the ten articles was done, which offered robust evidence supporting the need for the IUCR-HOUDINI project. After learning the significance of all the gathered evidence, findings were presented to the entire SCI interdisciplinary team, which resulted in the acquisition of the team's unified backing of the implementation for the proposed project IUCR-HOUDINI protocol.

Implementing the change project was the fifth step in the Iowa Model. During this facet of the implementation phase, the project manager identified unit champions. The project manager consulted and collaborated with the unit nurse manager and the interdisciplinary team in choosing the unit champions. Two certified rehabilitation registered nurses (CRRNs) were identified as the right individuals to function as the unit champions. Their peers acknowledged these nurses as experienced, highly motivated, dedicated, and had worked in the project unit for more than ten years. As unit champions, they both received training on the completed lesson plan (see Appendix G). Their principal responsibility was to support and communicate continuously with the project manager to encourage nurses to commit and accept nursing practice transformation at the bedside by applying the IUCR-HOUDINI protocol.

After completing their training, these two-unit champions took the IUCR-HOUDINI validation assessment test (see Appendix H) to demonstrate their competency on IUCRHOUDINI protocol application at the bedside. The unit champions were expected to achieve a $100 \%$ score on competency validation to be considered competent and skilled in applying the EB nurse-driven catheter removal protocol. The additional intervention in fulfilling the project was 
training the nursing staff on the IUCR-HOUDINI protocol. The training schedules were disseminated by posting flyers in the SCI unit (see Appendix I).

The staff training included administering multiple sessions lead by the project manager with the unit nursing educator's support. The planned staff training was conducted utilizing a PowerPoint developed by the project manager illustrated in Appendix J. The nursing staff training evaluation included their active participation in discussing the generated case scenarios (see Appendix K) and utilizing the UCRAT to guide the participants to select appropriate clinical decisions needed to remove IUC, guided by IUCR-HOUDINI protocol. The completed tool captured the associated clinical factors that the nurse must identify in deciding whether to remove the patient's IUC, as guided by IUCR-HOUDINI protocol. The purpose of this exercise was to evaluate the competency of nursing staff attendees on the application of the IUCRHOUDINI. The attendance and outcome of the competency test were collected at the end of the training to assist the project manager in identifying the competent nurses who were considered ready to initiate the IUCR-HOUDINI protocol at the targeted project site by using the generated staff rosters (see Appendix L).

The completion of the tasks mentioned above indicated that the full implementation of the project could begin. During implementation, the UCRAT was used to determine which patients would meet the nurse-driven IUC removal protocol criteria. Once the assessment was completed using the IUCR tool, the admitting nurse placed the tool in each patient's medical record. If the patient met the established criteria for nurse-driven IUC removal protocol, the nurse immediately discontinued the patient's IUC and documented this intervention in the patient's medical record. To continue the execution of the IUCR-HOUDINI protocol, the nurse was expected to monitor if the patient could void within four hours of catheter removal. If the 
patient failed to void after four hours, the nurse performed a bladder scan. If the bladder scan showed that a patient had a urinary residual of fewer than $150 \mathrm{ml}$, the attending physician was notified to evaluate the patient's condition further.

Conversely, during the bladder scan, if the bladder residual was more than $150 \mathrm{ml}$ but less than $300 \mathrm{ml}$, the nurse monitored the patient for another two hours. The intention was to assess for any urinary discomfort caused by urinary retention after completing the bladder scan. However, if the patient verbalized urinary discomfort, the nurse performed intermittent catheterization. If the patient did not have any bladder discomfort, the next step was for the nurse to perform another bladder scan. If the urinary residual was $300 \mathrm{ml}$ and above, the nurse performed intermittent catheterization. When the patient voided voluntarily after removing the IUC, the nurse still needed to perform a bladder scan to ensure that the patient's bladder was emptied completely. Comprehensive documentation of all the interventions mentioned above was captured in the patient medical records.

During the implementation period, the champions collaborated with the project manager to ensure the nurses adhered to the IUCR-HOUDINI protocol. Part of the implementation process was for the project manager to identify patients with an indwelling urinary catheter. The rationale for this action was to ensure daily assessment utilizing the UCRAT for the possibility of discontinuing the IUC and move the patient to regular bladder training. The unit champions gathered the completed assessment tool daily and submitted it to the project manager in preparation for data analysis.

In the Iowa Model, evaluating the practice change was the last step that needed to be completed. The data collection included gathering the number of UCRAT forms completed by the bedside nurses, which collected information on catheter removal's total occurrences utilizing 
the IUCR-HOUDINI protocol during the project implementation period. Additionally, the project manager completed a retrospective chart review utilizing the "Catheter Removal Audit Tool" (see Appendix M) to determine project implementation efficacy, which was evidenced by a decrease in IUC days and reduced CAUTI.

\section{Gantt}

Adherence to the project timeline was essential for the successful completion of the project. The Gantt described the phases over the project's timeline and kept the task on schedule. It also helped circumscribe the elements needed for the EBP implementation with the corresponding allotted time, which served as guidance for executing each identified task (Sharon \& Dori, 2017). The Gantt showcases the simplified milestones of the specified task required to complete the project, as shown in Appendix N.

\section{Budget}

The monetary requirement for the implementation of the project on the IUCR-HOUDINI protocol was minimal. The meeting hours of this project with nurses and administration were one of the direct costs for the organization. The average salary of a registered nurse (RN) is $\$ 45 / \mathrm{hr}$., and there are approximately thirty-five RNs who needed to receive the training of the IUCRHOUDINI nurse-driven protocol. The project training was an hour and was supported by the unit nurse manager by allocating a monetary budget for staff training. For those nurses who missed the in-service, an accessible instructional program was available on the facility's intranet. The project's overall cost, which included staff salaries and supplies, was $\$ 3,404$ dollars (see Appendix O). 


\section{Evaluation Results}

The primary outcomes measured were the number of IUC days and CAUTI occurrences. The target participants selected for the project were the adult SCI patients admitted to the acute SCI rehabilitation unit during the six-week project implementation period. During the implementation period, only five patients met the inclusion criteria for the project. The UCRAT guided by HOUDINI protocol was used to assess patients' readiness for IUC removal. The influence of the HOUDINI protocol was evaluated by collecting the number of catheter days and CAUTI rates before and during the project timeframe. The privacy of patients was protected by aggregating and de-identifying the health records and the data used. The platform for securing data confidentiality was guaranteed from data collection and interpretation of the data. The ethical consideration to preserve human rights was always a priority even before the project began. The hospital Evidence-Based Practice Review Committee (EPRC) and the University of St. Augustine approved the project. Descriptive statistics were used to analyze and evaluate the data.

\section{Urinary Catheter Removal Assessment Tool}

The UCRAT, guided by the IUCR-HOUDINI protocol, was employed during project implementation. The tool was created in collaboration with a rehabilitation clinical nurse specialist (CNS) with permission awarded by Barnes-Jewish Christian (BJC) healthcare leaders who developed the protocol, as shown in Appendix P. The purpose of the tool was to assist and guide the nursing staff on how to properly utilize the implemented guidelines of the IUCRHOUDINI protocol on SCI patients. The face validity of the generated tool was obtained by having the rehabilitation CNS and the interdisciplinary team examine the UCRAT for the appropriateness of use in the target participants. The unit champions also examined the tool for 
understandability and clarity of its intended purpose. The project manager evaluated the reliability of the catheter assessment tool in collaboration with the rehabilitation CNS. This was done by having two different nurses appraise the SCI patient scenarios (see Appendix K) using the UCRAT, which confirmed similar results.

\section{Data Collection}

The data was collected during the project implementation period to evaluate the effectiveness of the IUCR-HOUDINI protocol on SCI patient outcomes related to IUC days and CAUTI occurrences. The pre-implementation baseline unit metrics were obtained from the infection control and preventionist nurse (ICPN). The pre-implementation metrics consisted of the number of patients admitted with IUCs, an average of catheter days, and CAUTI occurrences. The implementation unit metrics were captured for the six-week project period on a patient demographics such as gender and age, the number of patients admitted with catheters, the number of patients assessed with IUCR- HOUDINI protocol with qualifying and non-qualifying status, and occurrences of CAUTIs using the UCRAT (see Appendix F). The ICPN and the project manager collected the post-implementation data.

\section{Evaluation Design}

The data collected was analyzed using SPSS V27 statistical software's descriptive statistics, which consisted of demographics, the total number of IUC days, and occurrences of CAUTI before and during the project implementation. Descriptive data analysis was used to determine frequencies, means, standard deviation, percent and percent differences between the two independent groups. 


\section{Data Analysis}

The pre-intervention group (intervention $=$ No) consisted of seven patients, three females, and four males. Three patients were between 35-45 years of age, and four were above 45 years of age. In this group, the number of indwelling catheter days ranged from 4 to $15(M=6.86$ days, $\mathrm{SD}=4.41$ days), with a total of 48 catheter days. The earliest IUC removed was four days without the HOUDINI protocol, with one occurrence of CAUTI (14.29\%). The post-intervention group consisted of five patients, four males, and one female. Three patients were above 45 years of age, one patient between 35 and 45, and another patient between 25-35 years of age. For the post-intervention group (intervention $=$ Yes), the number of indwelling catheter days ranged from 2 to $43(\mathrm{M}=21.00$ days, $\mathrm{SD}=14.78$ days $)$, with a total of 105 catheter days. The earliest IUC removal was two days with the HOUDINI protocol application, with no occurrence of CAUTI.

In summary, the mean number of indwelling catheter days was greater for the postintervention group than the pre-intervention group, with a percent change of $119 \%$. However, implementing the EB IUCR-HOUDINI protocol promoted earlier catheter removal with a percentage change of $50 \%$ and improved patient outcomes related to CAUTIs to zero occurrences. Table 1 provides descriptive statistics of the number of indwelling urinary catheter days for both pre and post-intervention.

Table 1

Number of Indwelling Urinary Catheter Days

\begin{tabular}{lccclc}
\hline Intervention & $\mathrm{N}$ & Min & Max & $\mathrm{M}$ & $\mathrm{SD}$ \\
\hline No & 7 & 4.00 & 15.00 & 6.86 & 4.41 \\
Yes & 5 & 2.00 & 43.00 & 21.00 & 14.78
\end{tabular}




\section{Impact}

It is continuously challenging for health care organizations to secure the delivery and provision of safe, quality patient care. Consequently, CAUTIs can induce prolonged hospital stays, compromise patient safety, and become a financial burden on the organization (Dy, 2016). However, CAUTIs can be mitigated by implementing an EBP protocol, such as the one utilized for this project. Implementing the IUCR-HOUDINI protocol promoted IUC removal, reduced CAUTIs, and supported positive changes in the SCI unit to bridge the existing evidence-practice gap. The developed protocol increased collaboration between physicians and nurses to improve patient outcomes and allowed the daily assessment of the need for the IUC. Furthermore, it offered the frontline nurses the authority to remove the IUC if the reason for its presence did not meet the criteria as guided by IUCR-HOUDINI protocol. Before implementing the project, the SCI unit did not have a standardized protocol to address patients with an IUC. After implementing the project, the IUCR-HOUDINI protocol provided the frontline nurses the autonomy to remove IUC promptly, which reduced CAUTIs.

\section{Limitations}

There were few limitations identified for this project. The project was conducted at a single location solely with patients admitted with IUC or had IUC placed during their hospitalization. Another limitation was SCI admission decreased due to COVID-19, resulting in a small sample size.

\section{Sustainability}

The IUCR-HOUDINI protocol sustainability can be obtained by incorporating it in the registered nurse's unit-based orientation in the SCI rehabilitation unit. Also, a plan will be 
discussed with the EBP committee to extend the exploration of the IUCR- HOUDINI protocol throughout the selected organization's inpatient areas.

\section{Dissemination Plan}

Dissemination of the project's significant results will occur during the organization's monthly Interdisciplinary Hospital Infection Committee meeting through a 20 minutes PowerPoint presentation with handouts. The stakeholders who attend this meeting will include frontline staff, nurse managers, clinical educators, clinical nursing director, rehabilitation clinical nurse specialist, physicians, infection control preventionist nurse, physical therapist, occupational therapist, and support staff. Feedback from this team is vital for the EBP change to be successful. Results will also be presented to the EBP council, who will perform a peer review process, make recommendations for a practice change, and assist in disseminating the IUCRHOUDINI protocol. A copy of the PowerPoint presentation will be uploaded to the nursing portal to provide other staff access to the information at any given time.

Project results will be presented locally to the Department of Health Service's (DHS) annual safety conference via a poster presentation. The DHS conference attendees represent five network hospitals within the DHS, including multiple services throughout the ambulatory care network public health services. Regionally, the data and practice changes will be presented at the Los Angeles/Orange County Association of Rehab Nurses (LA/OC ARN) chapter and the annual Association of Rehabilitation Nursing (ARN) conference. Nationally, the results will be submitted for a poster or podium presentation at the American Nurses Credentialing Center (ANCC) Magnet 2022 conference.

For publication, an article will be submitted to the Journal of Rehabilitation Nursing due to its support of developing EB interventions to improve rehab patient outcomes. The article will 
be peer-reviewed by the EBP committee before submission.

\section{Conclusion}

The IUCR-HOUDINI protocol was aimed to promote the early removal of IUCs, reduce the rate of CAUTIs, and decrease the number of catheter days. Indeed, the analysis of the data indicated that there were no CAUTIs reported during the implementation period. However, the number of catheter days were increased due to patients' conditions requiring them to prolong their catheter removal, according to the project's established criteria. The IUCR-HOUDINI protocol's contribution was notably significant to nursing practice in the SCI unit. It served as a fundamental element of the nurses' decision-making in early IUC removal to minimize the prevalence of CAUTIs without necessitating physicians' orders. Additionally, it promoted nurses' autonomy at the bedside by solely ensuing the instituted protocol. Therefore, it is apparent that the EB IUCR-HOUDINI protocol delivered care transformation at the bedside by promoting nursing empowerment and advocacy towards quality care and patient safety. 


\section{References}

Aarons, G. A., Ehrhart, M. G., Farahnak, L. R., \& Hurlburt, M. S. (2015). Leadership and organizational change for implementation (LOCI): A randomized mixed method pilot study of a leadership and organization development intervention for evidence-based practice implementation. Implementation Science, 10(1), 40-64. https://doi.org/10.1186/s13012-014-0192-y

Adams, D., Bacoor, H., Day, G., \& Rammer, J. A. (2012). HOUDINI: make that urinary catheter disappear - nurse-led protocol. Journal of Infection Prevention, 13(2), 44-46. https://doi.org/10.1177/1757177412436818

Agency for Healthcare Research and Quality (2015). Toolkit for reducing catheter associated urinary tract infections in hospital units: Implementation guide. https://www.ahrq.gov/sites/defaults/files/publications/files/implementation-guide_0.pdf

American Nurses Association (ANA) 2016. Code of ethics for nurses. http://www.nursingworld.org/codeofethics

Ballard, J. P. Parsons, S., Rodgers, J., Mossback, V., Starks, B., (2018). HOUDINI impacts on utilization and infection rates. Urologic Nursing, 38(4), 184-191 https://doi.org/10.7257/1053-816X.2018.38.4.184

Barwick, M.A. (2011). Checklist to assess organizational readiness (CARI) for EIP implementation.http://www.effectiveservices.org/downloads/Checklist_to_Assess_Organ isational_Readiness_for_Implementation.pdf

Bernard, M.S, Hunter, K.F., \& Moore, K. N. (2012). A review of strategies to decrease the duration of indwelling catheters and potentially reduce the incidence of catheter 
associated urinary tract infections Urologic Nursing, 32(1), 29-37

http://www.ncbi.nlm.nih.gov/pubmed22474863

BJC Healthcare (2013). https://www.advisory.com/-/media/Advisorycom/Research/NEC/Events/Webconference/2013/Expanding-Nurse-Clinical-DecisionMaking-Urinary-Catheter-Removal.pdf

Buckwalter, K. C., Cullen, L., Hanrahan, K., Kleber, C., McCarthy, A. M., Rake, B., Steelman, V., Tripp, R. T., \& Tucker, S. (2017). Iowa Model of Evidence-Based Practice: Revisions and Validation. Worldviews on Evidence-Based Nursing, 14(3), 175-182. https://doi.org/10.1111/wvn.12223

Cardenas, D. D., Hoffman, J. M., Kirshbaum, S., \& McKinley, W. (2004). Etiology and incidence of rehospitalization after traumatic spinal cord injury: A multicenter analysis. Archives of Physical Medicine and Rehabilitation, 85(11), 1757-1763. https://doi.org/10.1016/j.apmr.2004.03.016

Centers for Disease Control and Prevention. (2015). Catheter-associated urinary tract infections (CAUTIs). https://www.cdc.gov/hai/ca_uti/uti.html

Center for Disease Control and Prevention. (2018a). Catheter-associated urinary tract infections (CAUTIs). https://www.cdc.gov/hai/ca_uti/uti.html

Centers for Medicare \& Medicaid Services. (2017). Hospital-acquired condition reduction program (HACRP). https://www.cms.gov/Medicare/Medicare-Fee-for$\underline{\text { Service-Payment/AcuteInpatientPPS/HAC-Reduction-Program.html }}$

Doody, C. M., \& Doody, O. (2011). Introducing evidence into nursing practice: using the IOWA model. British Journal of Nursing, 20 (11), 661-664. http://www.ncbi.nlm.nih.gov/pubmed/21727852 
Dy, S. (2016). A nurse-driven protocol for removal of indwelling urinary catheters across a multi-hospital academic healthcare system. Urologic Nursing, 36(5), 243-249. https://doi.org/10.7257/1053-816X.2016.36.5.243

Gesmundo, M. (2016). Enhancing nurses' knowledge on catheter-associated urinary tract infection (Cauti) prevention. Kai Tiaki Nursing Research, 7(1), 32-40. $\underline{\text { http://search.ebscohost.com/login.aspx?direct=true \&db=ccm\&AN=119345448\&site=eds }}$ -live.

Hennessey, Derek B., N. Kinnear, L. MacLellan, C. E. Byrne, J. Gani, and A. K. Nunn. (2019). The effect of appropriate bladder management on urinary tract infection rate in patients with a new spinal cord injury: A prospective observational study. World Journal of Urology, 10(1), 2183-2189. Doi: 10.1007/s00345-018-02620-7.

Hickey, J. V., \& Giardino, E. R. (2019). The role of the nurse in quality improvement and patient safety. Journal of Neurological \& Neurosurgical Nursing, 8(1), 30-36. https://doi.org/10.15225/PNN.2019.8.1.5

Huang, X., Kristal, M. M., \& Schroeder, R. G. (2010). The impact of organizational structure on mass customization capability: A contingency view. Production \& Operations Management, 19 (5), 515-530. https://doi.org/10.1111/j.1937-5956.2009.01117

Institute for Healthcare Improvement (2014). The breakthrough series. IHIs collaborative model for achieving breakthrough improvement. http://www.ihi.org

Institute of Medicine (2010). The future of nursing: Leading change, advancing health http//www.iomeduReports/2010/The-Future-of-Nursing-Leading-Change-Advancing$\underline{\text { Health.aspx }}$ 
Johnson, P., Gilman, A., Lintner, A., \& Buckner, E. (2016). Nurse-driven catheter-associated urinary tract infection reduction process and protocol. Critical Care Nursing Quarterly, 39(4), 352-362.

http://search.ebscohost.com/login.aspx?direct=true \&db=edo\&AN=118070477\&site=edslive.

Joint Commission (2015). 2015 National patient safety goals http://wwwjointcommission.org/standards_information/npsgs.aspx

Kline, R. B. (2011). Principles and practice of structural equation modeling, (3rd ed). New York: The Guilford Press.

Longest, B. B., \& Darr, K. (2014). Managing health services organizations and systems, (6 ${ }^{\text {th }}$ ed). Health Professions Press, Inc.

Mavin, C., \& Mills, G. (2015). Using quality improvement methods to prevent catheterassociated UTI. British Journal of Nursing, 24 (6), 22-28. https://doi.org/10.12968/bjon.2015.24.Sup18.S22

Maxwell, M., Murphy, K., \& McGettigan, M. (2018). Changing ICU culture to reduce catheterassociated urinary tract infections. Canadian Journal of Infection Control, 33(1), 39-43. $\underline{\text { http;//search.ebscohost.com/login.aspx?direct=true \&db=com\&AN=129292281\&site=eds }}$ $\underline{\text {-live }}$

Melany, B. M., \& Fineout-Overholt, E. (2015). Evidence-based practice in nursing and healthcare. A guide to best practice (3rd ed.). Philadelphia, PA: Lippincott Williams \& Wilkins.

Mitchell, G. (2013). Selecting the best theory to implement planned change. Nursing Management - UK, 20(1), 32-37. https://doi-org.prxusa.lirn.net/10.7748/nm2013.04.20.1.32.e1013 
Moher, D., Liberati, A., Tetzlaff, J., Altman, D.G., (2009). The PRISMA Group. Preferred reporting items for systematic reviews and meta-analyses: The PRISMA statement. PLoS Med 6(7): e1000097. doi:10.1371/journal.pmed1000097

Mori, C, (2014). A voiding catastrophe. Implementing a nurse driven protocol. MedSurg Nursing 23(1), 15-28. http://search.ebscohost.com/login.aspx?direct=true\&db=ccm\&AN=107891839\&site=eds $\underline{\text {-live. }}$

National Healthcare Safety Network. (2015). Operational guidance for acute care hospitals to report catheter-associated urinary tract infections (CAUTI) data to CDCs'for the purpose of fulfilling CMS's hospital inpatient quality reporting (IQR)requirements. https://www.cdc.gov/nhsn/pdfs/cms/Final-ACH-CAUTIGuidance_2015.pdf

Olson-Sitki, K., Kirkbride, G. \& Forbes, G. (2015). Evaluation of a nurse driven protocol to remove urinary catheters. Nurses' perceptions. Urologic Nursing, 35(2), 94-99. https://doi.org/10.7257/1053-816X.2015.35.2.94

Ong, B., Wilson, J. R., \& Henzel, M. K. (2020). Management of the patient with chronic spinal cord injury. Medical Clinics of North America, 104(2), 263-278. https://doi.org/10.1016/j.mcna.2019.10.006

Rahimi, M., Farhadi, K., Babaei, H., \& Soleymani, F. (2019). Prevention and management catheter-associated urinary tract infection in intensive care unit. Journal of Nursing \& Midwifery Sciences, 6(2), 98-103. https://doi.org/10.4103/JNMS.JNMS_47_18

Rancho Los Amigos National Rehabilitation Center. (n.d.). Los Angeles County Department of Health Services-Rancho Los Amigos home http://dhs.lacounty.gov/wps/portal/dhs/rancho 
Roth, J. D., Pariser, J. J., Stoffel, J. T., Lenherr, S. M., Myers, J. B., Welk, B., \& Elliott, S. P. (2019). Patient subjective assessment of urinary tract infection frequency and severity is associated with bladder management method in spinal cord injury. Spinal Cord, 57(8), 700-707. https://doi.org/10.1038/s41393-019-0268-2

Salameh, A., Mohajer, M. A., \& Daroucihe, R. O. (2015). Prevention of urinary tract infections in patients with spinal cord injury. CMAJ: Canadian Medical Association Journal, 187(11), 807-812 http://search.ebscohost.com/login.aspx?direct=true\&db=edsgsc\&AN=edsgcl.424532221 $\underline{\text { site }=\text { eds-live. }}$

Scanlon, K. A., Wells, C., Woolforde, L., Khameraj, A., \& Baumgarten, J., (2017). Saving lives and reducing harm: A cauti reduction program. Nursing Economic\$, 35(3), 134-141 https://doi.org/10.3928/00220124-20180718-08

Sharon, A., \& Dori, D. (2017). Model-based project-product lifecycle management and gantt chart models: A comparative study. Systems Engineering, 20(5), 447-466. https://doi.org/10.002/sys.21407

Shea, C. M., Jacobs, S. R., Esserman, D. A., Bruce, K., \& Weiner, B. J. (2014). Organizational readiness for implementing change: a psychometric assessment of a new measure. Implementation Science, 15(1). 350-355. https://doi.org/10.1186/1748-5908-9-7

Silver, S. A., McQuillan, R., Harel, Z., Weizman, A. V., Thomas, A., Nesrallah, G., Bell, C. M., Chan, C. T., \& Chertow, G. M. (2016). How to sustain change and support continuous quality improvement. Clinical Journal of The American Society of Nephrology 11(5), 916-924. https://doi.org/10.2215/CJN.11501015 
Timmons, B., Vess, J., \& Conner, B. (2017). Nurse-driven protocol to reduce indwelling catheter dwell time. Journal of Nursing Care Quality, 32(2), 104. https://doi.org/10.1097/NCQ.0000000000000221

Titler, M. G., Kleiber, C., Steelman, V. J., Rakel, B. A., Budreau, G., Everett, L. Q., Buckwalter, K. C., Tripp-Reimer, T., \& Goode, C. J. (2001). The Iowa Model of Evidence-Based to Promote Quality Care. Critical Care Nursing Clinics of North America, 13(4), 497-509. https://doi.org/10.1016/S0899-5885(18)30017-0

Underwood, L. (2015). The effect of implementing comprehensive unit-based safety program on urinary catheter use. Urologic Nursing, 36(6), 271-279. doi:107257/1053$\underline{816 X .2015 .35 .6 .271}$

Zurmehly, J. (2018). Implementing a nurse-driven protocol to reduce catheter-associated uinary tract infections in a long-term acute care hospital. Journal of Continuing Education in Nursing, 49(8), 372-377. https://doi.org/10.3928/00220124-20180718-08 
Appendix A

\section{PRISMA Flow Diagram}
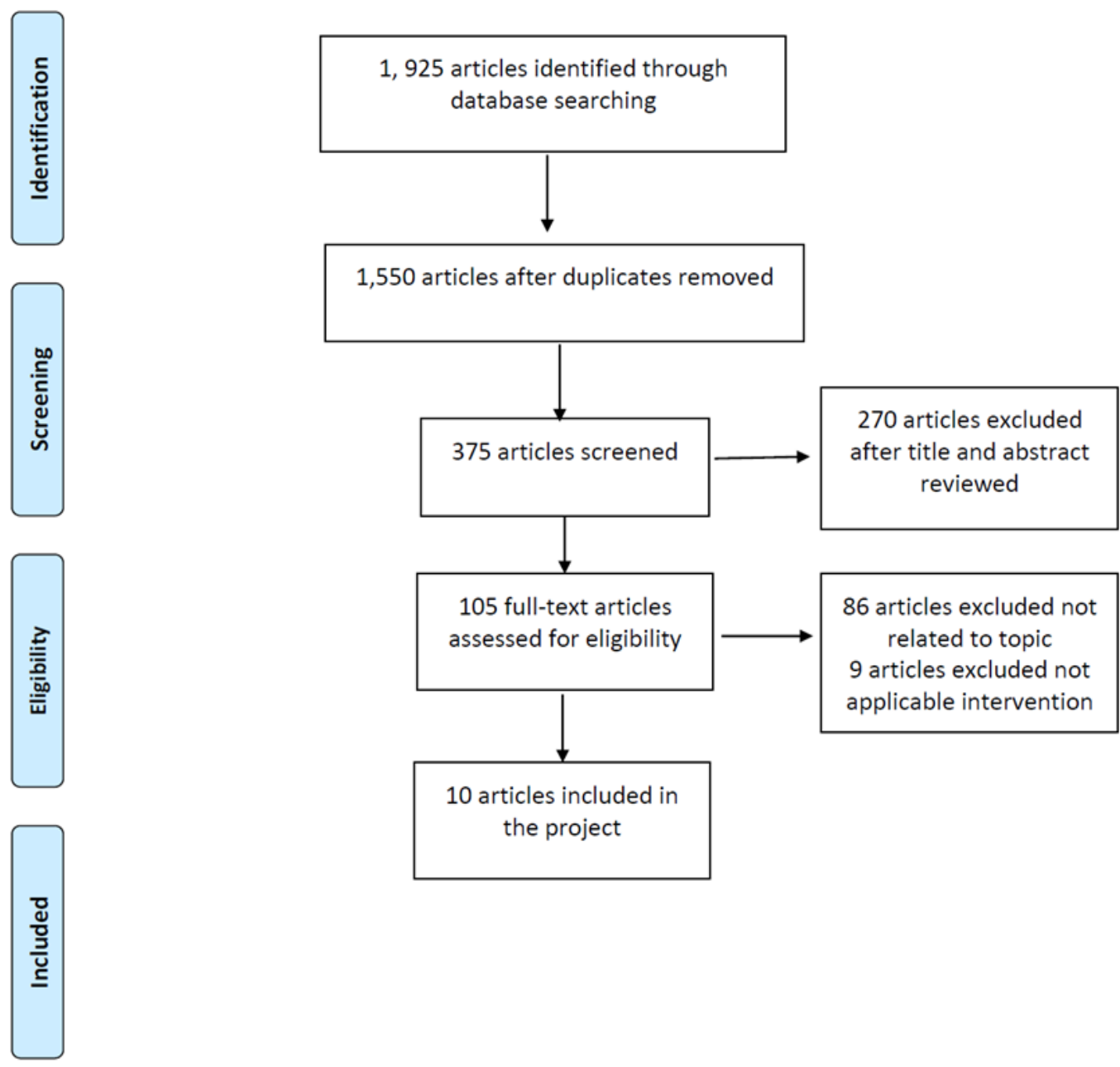

(Moher, Liberati, Tetzlaff \& Altman, 2009) 


\section{Appendix B}

\section{Summary of Primary Research Evidence}

\begin{tabular}{|c|c|c|c|c|c|c|}
\hline Citation & $\begin{array}{l}\text { Design } \\
\text { Level of } \\
\text { Evidence }\end{array}$ & $\begin{array}{l}\text { Sample } \\
\text { Sample size }\end{array}$ & $\begin{array}{l}\text { Intervention } \\
\text { Comparison }\end{array}$ & $\begin{array}{l}\text { Theoretical } \\
\text { Foundation }\end{array}$ & Measurement & $\begin{array}{l}\text { Usefulness } \\
\text { Results } \\
\text { Key Findings }\end{array}$ \\
\hline $\begin{array}{l}\text { Ballard, J. P. Parsons, S., } \\
\text { Rodgers, J., Mosack, V., Starks, } \\
\text { B., (2018). HOUDINI impacts } \\
\text { on utilization and infection rates. } \\
\text { Urologic Nursing, 38(4), 184- } \\
191 \\
\underline{\text { https://doi.org/10.7257/1053- }} \\
\text { 16X.2018.38.4.184 }\end{array}$ & $\begin{array}{c}\text { Retrospective } \\
\text { study } \\
\text { Level III }\end{array}$ & $\begin{array}{c}\text { Patients admitted } \\
\text { to medical unit } \\
\text { from } \\
\text { January } 2015 \text { thru } \\
\text { July } 2015 \\
\text { pre } \\
\text { 3,565 patients } \\
\text { pre } \\
\text { (implementation) } \\
\text { 3, } 699 \text { patients } \\
\text { post } \\
\text { (implementation) } \\
\text { January } 2016 \\
\text { to } \\
\text { July } 2016\end{array}$ & $\begin{array}{l}\text { The data were collected from } \\
\text { identified database restricted to patient } \\
\text { care days, catheter days, catheter } \\
\text { utilization ratios, and number of } \\
\text { CAUTIs. Pre and post-interventions } \\
\text { were examined. Thorough training } \\
\text { with staff concerning the nurse-driven } \\
\text { removal of urinary catheters executed } \\
\text { before the change initiative. } \\
\text { Two-tailed paired-samples t-tests } \\
\text { discovered the influence of the NDRP. } \\
\text { The two-tailed paired samples t-test } \\
\text { was also employed for patient days } \\
\text { and catheter days per patient. These } \\
\text { data were examined in a pre- and post- } \\
\text { method to determine the impact of the } \\
\text { implementation of CUSP-driven } \\
\text { improvement initiative applying } \\
\text { HOUDINI guidelines. HOUDINI } \\
\text { stands for: } \\
\text { i. Hematuria, gross } \\
\text { ii. Obstruction, urinary } \\
\text { iii. Decubitus ulcer } \\
\text { iv. Intake and output } \\
\text { v. No code/comfort care } \\
\text { vi. Immobility }\end{array}$ & $\begin{array}{l}4 \text { E's model } \\
\text { engagement, } \\
\text { education, } \\
\text { execution and } \\
\text { evaluation }\end{array}$ & $\begin{array}{l}\text { The } \\
\text { measurement of } \\
\text { the study entails } \\
\text { rates of CAUTI } \\
\text { and } \\
\text { catheterization } \\
\text { days }\end{array}$ & $\begin{array}{l}\text { The usefulness of the study } \\
\text { provide staff with increased } \\
\text { awareness } \\
\text { of the appropriate implications } \\
\text { of an indwelling urinary } \\
\text { catheter to reduce indwelling } \\
\text { urinary catheter use and } \\
\text { catheter-associated urinary tract } \\
\text { infections (CAUTI). } \\
\text { The key findings of the study } \\
\text { determined the application of } \\
\text { the NDRP-HOUDINI protocol } \\
\text { exhibit decreases in catheter } \\
\text { utilization without statistically } \\
\text { significant reductions in } \\
\text { CAUTI. Improving the power } \\
\text { of the method for both catheter } \\
\text { insertion and removal may } \\
\text { direct to further notable gains. } \\
\text { Also, the use of NDRP } \\
\text { promotes independent nursing } \\
\text { practice and full professional } \\
\text { role fulfillment through } \\
\text { collaborative practice. }\end{array}$ \\
\hline $\begin{array}{l}\text { Johnson, P., Gilman, A., Lintner, } \\
\text { A., \& Buckner, E. (2016). } \\
\text { Nurse-driven catheter-associated } \\
\text { urinary tract infection reduction } \\
\text { process and protocol. Critical } \\
\text { Care Nursing Quarterly, 39(4), } \\
352 . \\
\text { http://search.ebscohost.com/logi } \\
\underline{\text { n.aspx?dircet=true\& }}\end{array}$ & $\begin{array}{c}\text { Interventional } \\
\text { study } \\
\text { Level III }\end{array}$ & $\begin{array}{l}4 \text { ICUs for }>8 \\
\text { months pre and } \\
\text { post protocol }\end{array}$ & $\begin{array}{l}\text { To determine whether there were } \\
\text { clinical determinants that contributed } \\
\text { to the increase of CAUTIs in the } \\
\text { ICUs, baseline surveillance data were } \\
\text { collected. Also, retrospective review } \\
\text { of baseline data (number of CAUTIs } \\
\text { and number of catheter days) across } \\
\text { multiple units unveiled that the } \\
\text { CAUTI rate for the combined units }\end{array}$ & $\begin{array}{l}\text { ICARE } \\
\text { performance } \\
\text { improvement } \\
\text { methodology } \\
\text { (identify, } \\
\text { clarify, } \\
\text { analysis, } \\
\text { revision, and } \\
\text { educate). }\end{array}$ & $\begin{array}{c}\text { The } \\
\text { measurement of } \\
\text { the study } \\
\text { pertains to } \\
\text { CAUTI rates } \\
\text { and catheter } \\
\text { days }\end{array}$ & $\begin{array}{l}\text { The key findings of the study } \\
\text { depicted that nursing staff's } \\
\text { eagerness to implement tests of } \\
\text { change and contribution to } \\
\text { quality improvement processes } \\
\text { led to the protocol success. } \\
\text { Also, nurses feel empowered as } \\
\text { they realize that they have the } \\
\text { support of the organization and }\end{array}$ \\
\hline
\end{tabular}




\begin{tabular}{|c|c|c|c|c|c|c|}
\hline $\begin{array}{l}\text { db.=edo\&AN=118070477\&site }= \\
\text { eds.live }\end{array}$ & & & $\begin{array}{l}\text { was } 0.60 \% \text { ( } 25 \text { CAUTIs per } 4154 \\
\text { catheter days). }\end{array}$ & $\begin{array}{l}\text { Plan-do-study- } \\
\text { act } \\
\text { (PDSA) }\end{array}$ & & $\begin{array}{l}\text { can enhance their skills in } \\
\text { performing changes to patient } \\
\text { care that are based on EBP. }\end{array}$ \\
\hline $\begin{array}{l}\text { Maxwell, M., Murphy, K., \& } \\
\text { McGettigan, M. (2018). } \\
\text { Changing ICU culture to reduce } \\
\text { catheter-associated urinary tract } \\
\text { infections. Canadian Journal of } \\
\text { Infection Control, 33(1), 39-43. } \\
\text { http;//search.ebscohost.com/logi } \\
\underline{\text { n.aspx?direct=true }} \\
\underline{\mathrm{\& db}=\text { com\&AN=129292281\&sit }} \\
\underline{\mathrm{e}=\mathrm{eds}-\mathrm{live}}\end{array}$ & $\begin{array}{l}\text { Qualitative } \\
\text { study } \\
\text { Level III }\end{array}$ & $\begin{array}{c}\text { All patients } \\
\text { admitted in the } \\
\text { ICU of Colorado } \\
\text { Hospital } \\
\text { who were } \\
\text { catheterized from } \\
\text { January } 1,2015 \\
\text { to } \\
\text { December } 31 \text {, } \\
2016\end{array}$ & $\begin{array}{l}\text { The ICU team, including nurses, } \\
\text { physicians, and CNAs, were provided } \\
\text { education regarding the changes in } \\
\text { catheter care, appropriate utilization, } \\
\text { and catheter placement options. Also, } \\
\text { training included emptying the } \\
\text { catheter bag at } 350 \mathrm{ml} \text { to } 500 \mathrm{ml} \text { or } \\
\text { every four hours and before patient } \\
\text { transport, ambulation, or transfer. } \\
\text { Statistical process control charts were } \\
\text { used in the monitoring of device days } \\
\text { and CAUTI events. The charts were } \\
\text { examined visually by the project team, } \\
\text { and any qualitative or statistical } \\
\text { deviations were recorded and } \\
\text { analyzed. }\end{array}$ & $\begin{array}{l}\text { Plan-do-study- } \\
\text { act } \\
\text { (PDSA) }\end{array}$ & $\begin{array}{l}\text { The study's } \\
\text { measurement } \\
\text { includes } \\
\text { indwelling } \\
\text { catheter use, } \\
\text { CAUTI rates } \\
\text { and catheter } \\
\text { days }\end{array}$ & $\begin{array}{l}\text { The study's usefulness for } \\
\text { nurses must continuously } \\
\text { revisit the intervention } \\
\text { measures. Also, consideration } \\
\text { must be given to stay informed } \\
\text { of current evidence-based } \\
\text { practice, new products, and } \\
\text { careful onboarding of new staff. } \\
\text { The study's key findings } \\
\text { illustrated a reduction in harm } \\
\text { to the ICU patient, while } \\
\text { determining best practices with } \\
\text { indwelling urinary catheter for } \\
\text { CAUTI prevention. }\end{array}$ \\
\hline $\begin{array}{l}\text { Mori, C, (2014). A voiding } \\
\text { catastrophe. Implementing a } \\
\text { nurse driven protocol. MedSurg } \\
\text { Nursing 23(1), 15-28. } \\
\text { http://search.ebscohost.com/logi } \\
\underline{\text { n.aspx?direct= }} \\
\underline{\text { true\&db=ccm\&AN=107891839 }} \\
\text { \&site=eds-live. }\end{array}$ & $\begin{array}{c}\text { Quantitative } \\
\text { study } \\
\text { Level III }\end{array}$ & $\begin{array}{l}\text { Any patient with } \\
\text { an indwelling } \\
\text { urinary catheter } \\
\text { during } \\
\text { hospitalization at } \\
150 \text { bed } \\
\text { community } \\
\text { hospital in } \\
\text { northern US. }\end{array}$ & $\begin{array}{l}\text { Developed a practice standard that } \\
\text { involved evidence-based guidelines to } \\
\text { support the need for an indwelling } \\
\text { catheter by multidisciplinary team of } \\
\text { clinical nurse specialists, infection } \\
\text { control staff, and physician. } \\
\text { A retrospective chart review provided } \\
\text { measurement of the prevalence of } \\
\text { catheter usage, dwell time, and } \\
\text { CAUTIs before and after } \\
\text { implementation of the protocol. }\end{array}$ & $\begin{array}{c}\text { Donabedian's } \\
\text { structure- } \\
\text { process- } \\
\text { outcome } \\
\text { model }\end{array}$ & $\begin{array}{c}\text { The } \\
\text { measurement of } \\
\text { the study } \\
\text { includes } \\
\text { indwelling } \\
\text { catheter usage, } \\
\text { dwell time and } \\
\text { number of } \\
\text { CAUTIs }\end{array}$ & $\begin{array}{l}\text { The study's usefulness results } \\
\text { empower nurses to utilize a } \\
\text { nurse-driven protocol in } \\
\text { discontinuing the urinary } \\
\text { catheter independently when } \\
\text { the indications are no longer } \\
\text { met to reduce CAUTI rates and } \\
\text { catheter days. } \\
\text { The nurse-driven protocol } \\
\text { significantly decreased the } \\
\text { duration of use for indwelling } \\
\text { catheters, and the incidence of } \\
\text { CAUTI and reducing the cost } \\
\text { of health care are the key } \\
\text { findings of the study. }\end{array}$ \\
\hline $\begin{array}{l}\text { Olson-Sitki, K., Kirkbride, G. \& } \\
\text { Forbes, G. (2015). Evaluation of } \\
\text { a nurse driven protocol to }\end{array}$ & $\begin{array}{l}\text { Descriptive } \\
\text { study } \\
\text { Level IV }\end{array}$ & $\begin{array}{l}91 \mathrm{RNs} \\
\text { from a } 500 \\
\text { Magnet }\end{array}$ & $\begin{array}{l}\text { A descriptive study adopted a self- } \\
\text { developed questionnaire to obtain } \\
\text { nurses' perceptions of the impact of an } \\
\text { indwelling urinary catheter removal }\end{array}$ & Unspecified & $\begin{array}{l}\text { The study's } \\
\text { measurement } \\
\text { includes the } \\
\text { perception of }\end{array}$ & $\begin{array}{l}\text { The study's usefulness is that } \\
\text { decreasing infection rates in } \\
\text { healthcare, for any reason, is a } \\
\text { constant challenge that no }\end{array}$ \\
\hline
\end{tabular}




\begin{tabular}{|c|c|c|c|c|c|c|}
\hline $\begin{array}{l}\text { remove urinary catheters. } \\
\text { Nurses' perceptions. } \\
\text { Urologic Nursing, 35(2), 94-99. } \\
\text { https://doi.org/10.7257/1053- } \\
\underline{\text { 816X.2015.35.2.94 }}\end{array}$ & & $\begin{array}{c}\text { designated } \\
\text { hospital }\end{array}$ & $\begin{array}{l}\text { protocol on job ease, empowerment, } \\
\text { job satisfaction, patient feedback, and } \\
\text { physician. Ninety-one (91) RNs } \\
\text { completed the questionnaire, and of } \\
\text { those, } 48 \text { practiced the removal } \\
\text { protocol. } \\
\text { Chi-square statistics was used to } \\
\text { examine the data. Nurses' } \\
\text { understandings of both job ease and } \\
\text { efficiency of nursing workflow were } \\
\text { significantly higher with the } \\
\text { utilization of the protocol. The less- } \\
\text { experienced RNs were more likely to } \\
\text { use the protocol. No significance was } \\
\text { observed in empowerment, job } \\
\text { satisfaction, or nurses' understandings } \\
\text { for practitioner feedback in those who } \\
\text { practiced the protocol. }\end{array}$ & & $\begin{array}{l}\text { the effect of a } \\
\text { protocol on job } \\
\text { ease, } \\
\text { empowerment, } \\
\text { job satisfaction, } \\
\text { patient and } \\
\text { provider } \\
\text { feedback }\end{array}$ & $\begin{array}{l}\text { organization can disregard for } \\
\text { any length of time. } \\
\text { Implementing a nurse-driven } \\
\text { protocol to reduce infection } \\
\text { rates is significant within the } \\
\text { nursing scope of practice, and } \\
\text { nurses are more likely to lower } \\
\text { infection rates, particularly } \\
\text { CAUTI, when specific } \\
\text { protocols are implemented. } \\
\text { The key findings of the study } \\
\text { reported a nurse-driven urinary } \\
\text { catheter removal protocol } \\
\text { implementation significantly } \\
\text { improved nurses' } \\
\text { understandings of job ease and } \\
\text { patient feedback. }\end{array}$ \\
\hline $\begin{array}{l}\text { Scanlon, K. A., Wells, C., } \\
\text { Woolforde, L., Khameraj, A., \& } \\
\text { Baumgarten, J., (2017). Saving } \\
\text { lives and reducing harm: A } \\
\text { CAUTI reduction program. } \\
\text { Nursing Economic\$, 35(3), 134- } \\
\text { 141.https://doi.org/10.3928/0022 } \\
\text { 0124-20180718-08 }\end{array}$ & $\begin{array}{c}\text { Quantitative } \\
\text { study } \\
\text { Level IV }\end{array}$ & $\begin{array}{l}\text { Northwell } \\
\text { University } \\
\text { hospital with } 814 \\
\text { bed capacity, the } \\
\text { 14th largest health } \\
\text { care system in the } \\
\text { United States. }\end{array}$ & $\begin{array}{l}\text { The project started with the } \\
\text { identification of } 188 \text { RNs CAUTI } \\
\text { ambassadors. Next was the } \\
\text { development of a straight } \\
\text { catheterization algorithm pocket card. } \\
\text { Followed by CAUTI training with } \\
\text { CAUTI ambassadors and staff on best } \\
\text { practice insertion and maintenance } \\
\text { guidelines. After the training, } \\
\text { implementation of interprofessional } \\
\text { rounds on all patients with indwelling } \\
\text { urinary catheters in real time to } \\
\text { discuss catheter situation, } \\
\text { opportunities for removal and } \\
\text { education opportunities. Lastly, the } \\
\text { construction of CAUTI acronym. } \\
\text { Measures of SIR incidence and } \\
\text { catheter days for Northwell Health in } \\
\text { the ICU area are the data collected. } \\
\text { SIR is employed as an index to } \\
\text { estimate infection performance, } \\
\text { measured by dividing the number of } \\
\text { identified infections by the number of } \\
\text { predicted infections. }\end{array}$ & $\begin{array}{c}\text { Plan-do-study- } \\
\text { act } \\
\text { (PDSA) }\end{array}$ & $\begin{array}{l}\text { The } \\
\text { measurement of } \\
\text { the study } \\
\text { centers on } \\
\text { CAUTI rates }\end{array}$ & $\begin{array}{l}\text { The study's usefulness has been } \\
\text { the development of evidence- } \\
\text { based protocol and autonomy } \\
\text { of frontline staff who maintain } \\
\text { to elevate their practice while } \\
\text { rendering safe quality care to } \\
\text { patients. } \\
\text { The key findings of the study } \\
\text { manifested that approach for } \\
\text { reducing CAUTI has confirmed } \\
\text { successfully. Also, changing } \\
\text { culture is vital to organizational } \\
\text { success, which can be obtained } \\
\text { by interprofessional } \\
\text { collaboration and team } \\
\text { development. The program has } \\
\text { improved confidence in } \\
\text { individuals and change in } \\
\text { practice can influence the } \\
\text { quality of care provided to } \\
\text { patients. }\end{array}$ \\
\hline $\begin{array}{l}\text { Timmons, B., Vess, J., \& } \\
\text { Conner, B. (2017). Nurse-driven }\end{array}$ & $\begin{array}{l}\text { Quantitative } \\
\text { study }\end{array}$ & $\begin{array}{l}\text { The sample } \\
\text { consisted of any }\end{array}$ & $\begin{array}{l}\text { Three-month baseline, and three- } \\
\text { month intervention period. Following }\end{array}$ & $\begin{array}{l}\text { Plan-do-study- } \\
\text { act }\end{array}$ & $\begin{array}{l}\text { Indwelling } \\
\text { catheter usage }\end{array}$ & $\begin{array}{l}\text { The study's usefulness for } \\
\text { implementing a simple, }\end{array}$ \\
\hline
\end{tabular}




\begin{tabular}{|c|c|c|c|c|c|c|}
\hline $\begin{array}{l}\text { protocol to reduce indwelling } \\
\text { catheter dwell time. Journal of } \\
\text { Nursing Care Quality, 32(2), } \\
\text { 104. } \\
\text { https://doi.org/10.1097/NCQ.000 } \\
000000000221 \\
\end{array}$ & Level III & $\begin{array}{l}\text { patient in the } \\
\text { Medical } \\
\text { University of } \\
\text { South Carolina } \\
\text { ICU with an } \\
\text { indwelling } \\
\text { catheter. }\end{array}$ & $\begin{array}{l}\text { the plan, do, study, act cycle model, } \\
\text { an NDP for IUC insertion and removal } \\
\text { by the nurse without a physician order } \\
\text { was implemented, based on } \\
\text { assessment of medical necessity. } \\
\text { Retrospective data gathering was } \\
\text { concluded by applying the charge } \\
\text { nurse's collection of insertion and } \\
\text { removal dates with occasional } \\
\text { retrospective chart reviews. Pre- and } \\
\text { post-intervention data were obtained } \\
\text { and equated to discover average dwell } \\
\text { time. Data were analyzed to determine } \\
\text { whether the protocol was useful in } \\
\text { reducing average catheter dwell time. }\end{array}$ & (PDSA) & $\begin{array}{c}\text { is the } \\
\text { measurement } \\
\text { focus of the } \\
\text { study }\end{array}$ & $\begin{array}{l}\text { evidence-based protocol can } \\
\text { dramatically decrease the total } \\
\text { incidence of hospital-acquired } \\
\text { CAUTI } \\
\text { The key findings of the study } \\
\text { confirmed using a nurse-driven } \\
\text { protocol to remove indwelling } \\
\text { catheters; nurses are provided } \\
\text { the autonomy to follow } \\
\text { guidelines to appropriately } \\
\text { manage urinary catheters } \\
\text { without the pressure of getting } \\
\text { a physician's catheter removal } \\
\text { order. Also, the use of a } \\
\text { standardized, evidence-based, } \\
\text { nurse-driven protocol } \\
\text { successfully decreased catheter } \\
\text { dwell time. }\end{array}$ \\
\hline $\begin{array}{l}\text { Underwood, L. (2015). The } \\
\text { effect of implementing a } \\
\text { comprehensive unit-based safety } \\
\text { program on urinary catheter use. } \\
\text { Urologic Nursing, } 35(6), 271- \\
279 . \\
\text { https://doi.org/10.7257/1053- } \\
\text { 816X.2015.35.6.271 }\end{array}$ & $\begin{array}{c}\text { Quantitative } \\
\text { study } \\
\text { Level III }\end{array}$ & $\begin{array}{l}\text { The sample } \\
\text { includes all } \\
\text { patients from } \\
\text { January } 2012 \text { to } \\
\text { June } 2012 \text { that } \\
\text { was admitted to } \\
\text { NNICU (pre- } \\
\text { implementation) } \\
\text { compared to all } \\
\text { the patient } \\
\text { admitted from } \\
\text { January } 2013 \text { to } \\
\text { June } 2013 \text { (post- } \\
\text { implementation). }\end{array}$ & $\begin{array}{l}\text { Implementation of CUSP combined } \\
\text { various aspects of urinary catheter } \\
\text { maintenance and care. These included } \\
\text { training the nursing staff of insertion } \\
\text { techniques, proper and timely catheter } \\
\text { use, positioning of drainage bag, when } \\
\text { to send urinalysis and culture, proper } \\
\text { documentation and immediate } \\
\text { removal of urinary catheters. } \\
\text { Patient monthly data were abstracted, } \\
\text { including total CAUTI, catheter } \\
\text { utilization, urinary catheter days, and } \\
\text { CAUTI rate. The result of CUSP on } \\
\text { catheter utilization and CAUTI was } \\
\text { discovered using independent } \\
\text { samples, t-tests, and Mann-Whitney U } \\
\text { tests. Implementing CUSP resulted in } \\
\text { decreased catheter utilization from } \\
89 \% \text { to } 75 \% \text { (p = 0.001) and clinical } \\
\text { reduction rate of CAUTI rate by 19\% } \\
\text { (from } 7.9 \text { to 7.2) }\end{array}$ & $\begin{array}{c}\text { None } \\
\text { mentioned }\end{array}$ & $\begin{array}{c}\text { The } \\
\text { measurement of } \\
\text { the study } \\
\text { comprises } \\
\text { CAUTI rates } \\
\text { indwelling } \\
\text { catheter usage } \\
\text { and nurse's } \\
\text { documentation }\end{array}$ & $\begin{array}{l}\text { The study's usefulness is that } \\
\text { nursing has a crucial role in } \\
\text { patient outcomes. There is a } \\
\text { need to provide them with the } \\
\text { evidence-based knowledge } \\
\text { required to advocate for } \\
\text { patients and perform the best } \\
\text { guidelines in their practice. } \\
\text { The study's findings suggest } \\
\text { that the implementation of } \\
\text { standards must be followed to } \\
\text { evade preventable } \\
\text { complications when employing } \\
\text { indwelling urinary catheters. } \\
\text { The catheters are a valuable } \\
\text { tool and essential in many ICU } \\
\text { patients, but they must be used } \\
\text { in the appropriate setting, or } \\
\text { they can lead to unnecessary } \\
\text { CAUTIs. }\end{array}$ \\
\hline $\begin{array}{l}\text { Zurmehly, J. (2018). } \\
\text { Implementing a nurse-driven } \\
\text { protocol to reduce catheter- } \\
\text { associated uinary tract infections } \\
\text { in a long-term acute care }\end{array}$ & $\begin{array}{c}\text { Quasi- } \\
\text { experimental } \\
\text { design } \\
\text { Level III }\end{array}$ & $\begin{array}{l}\text { A sample of } 70 \\
\text { RNs from three } \\
\text { various unit of a } \\
\text { long-term acute } \\
\text { care hospital. }\end{array}$ & $\begin{array}{l}\text { Implementation of urinary catheter } \\
\text { program based (UCP) based on the } \\
\text { best evidence that rendered guidelines } \\
\text { for nurses attending for CCI patients. } \\
\text { The actions constituted a revision of }\end{array}$ & Iowa model & $\begin{array}{l}\text { The CAUTI } \\
\text { rates and } \\
\text { nurse's } \\
\text { compliance } \\
\text { with }\end{array}$ & $\begin{array}{l}\text { The usefulness of the study is } \\
\text { providing the bedside nurse } \\
\text { with an evidence-based } \\
\text { protocol driven by patient } \\
\text { indications and diagnoses that }\end{array}$ \\
\hline
\end{tabular}




\begin{tabular}{|c|c|c|c|}
\hline $\begin{array}{l}\text { hospital. Journal of Continuing } \\
\text { Education in Nursing, } 49(8), \\
\text { 372-377. } \\
\text { https://doi.org/10.3928/0022012 } \\
\underline{4-20180718-08}\end{array}$ & $\begin{array}{l}\text { existing policy and introduction of } \\
\text { evidence-based UCP, competency } \\
\text { training for nurses, and evaluation of } \\
\text { CCI outcomes. } \\
\text { The SPSS }{ }^{\circ} \text { version } 21.0 \text { was applied } \\
\text { to analyze the data. Measures } \\
\text { examination of change was used to } \\
\text { compare nurses' knowledge and } \\
\text { performance of CAUTI prevention } \\
\text { before and after the intervention. }\end{array}$ & $\begin{array}{l}\text { the program is } \\
\text { the measures } \\
\text { known in the } \\
\text { study }\end{array}$ & $\begin{array}{l}\text { enables them to practice } \\
\text { autonomously in catheter } \\
\text { removal. Also, the timely } \\
\text { removal of indwelling urinary } \\
\text { catheters results in reduced } \\
\text { device days and decreased } \\
\text { incidence of CAUTIs. } \\
\text { The key findings of the study } \\
\text { demonstrated that CAUTI rates } \\
\text { could be significantly reduced } \\
\text { if foley catheter protocols } \\
\text { include best practice, and } \\
\text { educational approaches are } \\
\text { utilized to engage nurses in } \\
\text { quality care. }\end{array}$ \\
\hline
\end{tabular}

Legend: CAUTI Catheter-associated urinary tract infection; CCI Chronic Critically ill; CNA Certified Nursing Attendant; CUSP Comprehensive Unit-Based Safety Program; EBP Evidence Based Practice; ICU Intensive Care Unit; IUC Indwelling Urinary Catheter; NDP Nurse Driven Protocol; NDRP Nurse Driven Removal Protocol; NNICU Neurosurgical and Neurological Intensive Care Unit; RNs Registered Nurses; SIR Standardized Infection Ratio; SPSS Statistical Package for the Social Sciences. 
Appendix C

Summary of Systematic Reviews

\begin{tabular}{|c|c|c|c|c|c|c|c|}
\hline Citation & \begin{tabular}{|l|} 
Level of \\
Evidence
\end{tabular} & Question & Search Strategy & $\begin{array}{c}\text { Inclusion/ } \\
\text { Exclusion Criteria }\end{array}$ & \begin{tabular}{|c|} 
Data Extraction and \\
Analysis \\
\end{tabular} & Key Findings & \begin{tabular}{|c|} 
Usefulness/Recommendation/ \\
Implications \\
\end{tabular} \\
\hline \begin{tabular}{|l|} 
Durant, D, (2017). \\
Nurse driven protocols \\
and the prevention of \\
catheter-associated \\
urinary tract \\
infections: A \\
systematic review. \\
American Journal of \\
Infection Control 45 \\
(12), 1331-1341 \\
https://doi.org/10.1016 \\
(j.ajic.2017.07.020
\end{tabular} & | Level II & $\begin{array}{c}\text { Does nurse- } \\
\text { driven protocols } \\
\text { prevent catheter- } \\
\text { associated UTI? }\end{array}$ & \begin{tabular}{|l} 
The data searched \\
included CINAHL, \\
Medline, Health \\
Source, Nursing \\
Academic, Science \\
Direct, and Google \\
Scholar. In these \\
databases, titles and \\
abstracts were \\
searched for the \\
keywords and phrases \\
("nurse-driven OR \\
"nurse-directed") \\
AND (protocol" OR \\
intervention") AND \\
"catheter."
\end{tabular} & $\begin{array}{l}\text { Inclusion } \\
\text { Articles published after } \\
2006 \\
\text { Reviews that explore the } \\
\text { influence of the nurse- } \\
\text { driven protocol on clinical } \\
\text { outcomes such as IUC } \\
\text { utilization rates, IUC days, } \\
\text { and CAUTI rates } \\
\text { Patient in the acute care } \\
\text { settings in the United States } \\
\text { Exclusion } \\
\text { Articles that are not meeting } \\
\text { the above criteria } \\
\text { Editorials and pieces of } \\
\text { views rather than reports of } \\
\text { intervention }\end{array}$ & \begin{tabular}{|l} 
The search of \\
electronic databases \\
initially regained 112 \\
references. The \\
itemization of the \\
references was as \\
follows: CINAHL= \\
17; Medline $=43$, \\
Health \\
Source/Nursing \\
Academic $=12$, \\
Science Direct $=17$, \\
and Google Scholar $=$ \\
23 records. After \\
removing duplicates, \\
36 records were \\
screened for \\
eligibility based on \\
titles, resulting in 9 \\
exclusions; 27 \\
records were then \\
screened for \\
eligibility based on \\
the abstract. Of these, \\
three were excluded, \\
and 24 records were \\
retrieved for full-text \\
screening. Of the 24 \\
full-text records \\
screened, two were \\
eliminated. Also, \\
hand searching of the \\
references identified \\
seven more studies of \\
selected materials. \\
The final 29 \\
publications were \\
journaled articles.
\end{tabular} & $\begin{array}{l}\text { The significant findings } \\
\text { of the } 29 \text { articles all } \\
\text { were case-control } \\
\text { studies of a single group, } \\
\text { with a pre-post design. } \\
\text { These included all } \\
\text { patients on a unit or } \\
\text { hospital-wide with the } \\
\text { urinary catheter at a } \\
\text { given time, compared } \\
\text { with a retrospective } \\
\text { chart review. Most of } \\
\text { the studies centered their } \\
\text { attention on the } \\
\text { implementation of the } \\
\text { nurse-driven protocol; } \\
\text { however, few executed } \\
\text { several interventions } \\
\text { concurrently. They all } \\
\text { had similar designs, } \\
\text { applying a decision- } \\
\text { making algorithm for } \\
\text { catheter insertion and } \\
\text { removal based on } \\
\text { medical need criteria. }\end{array}$ & $\begin{array}{l}\text { The study's recommendation is } \\
\text { to use strategies to reduce } \\
\text { CAUTI and improve patient } \\
\text { outcomes through the } \\
\text { application of accepted } \\
\text { evidence-based prevention. The } \\
\text { most cost-effective method to } \\
\text { reduce CAUTI rate is to insert } \\
\text { catheters only for appropriate } \\
\text { indications and remove them } \\
\text { immediately when no longer } \\
\text { medically needed. } \\
\text { The implication of the study has } \\
\text { a positive impact on CAUTI. } \\
\text { The implementation of a nurse- } \\
\text { driven protocol appears to } \\
\text { dramatically reduce the clinical } \\
\text { predictors and prevalence of } \\
\text { CAUTI by improved } \\
\text { assessment of the medical } \\
\text { necessity and timely catheter } \\
\text { removal. }\end{array}$ \\
\hline
\end{tabular}

Legend: CAUTI Catheter-associated urinary tract infection; CINAHL Nursing and Allied Health Literature 


\section{Appendix D}

\section{SWOT Analysis}

\section{Strengths}

Strong administration support

Sustainable change

Organizational readiness for change

Improve staff satisfaction

\section{Opportunities}

CAUTI rate reduction

Decrease urinary catheter use Improve patient outcomes

Improve patient satisfaction

\section{Weaknesses}

Lack of staff buy in

Patient increased length of

stay

Financial burden

\section{Threats}

New protocol

Learning curve

Financial reimbursement tied to $\mathrm{CMS}$ 


\section{Appendix E}

Indwelling Urinary Catheter Removal HOUDINI Nurse-Driven Protocol
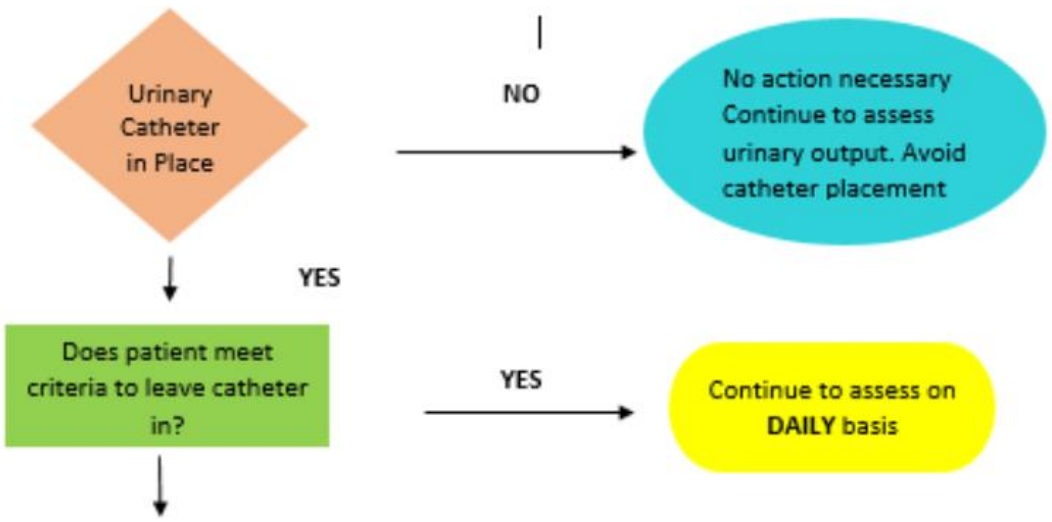

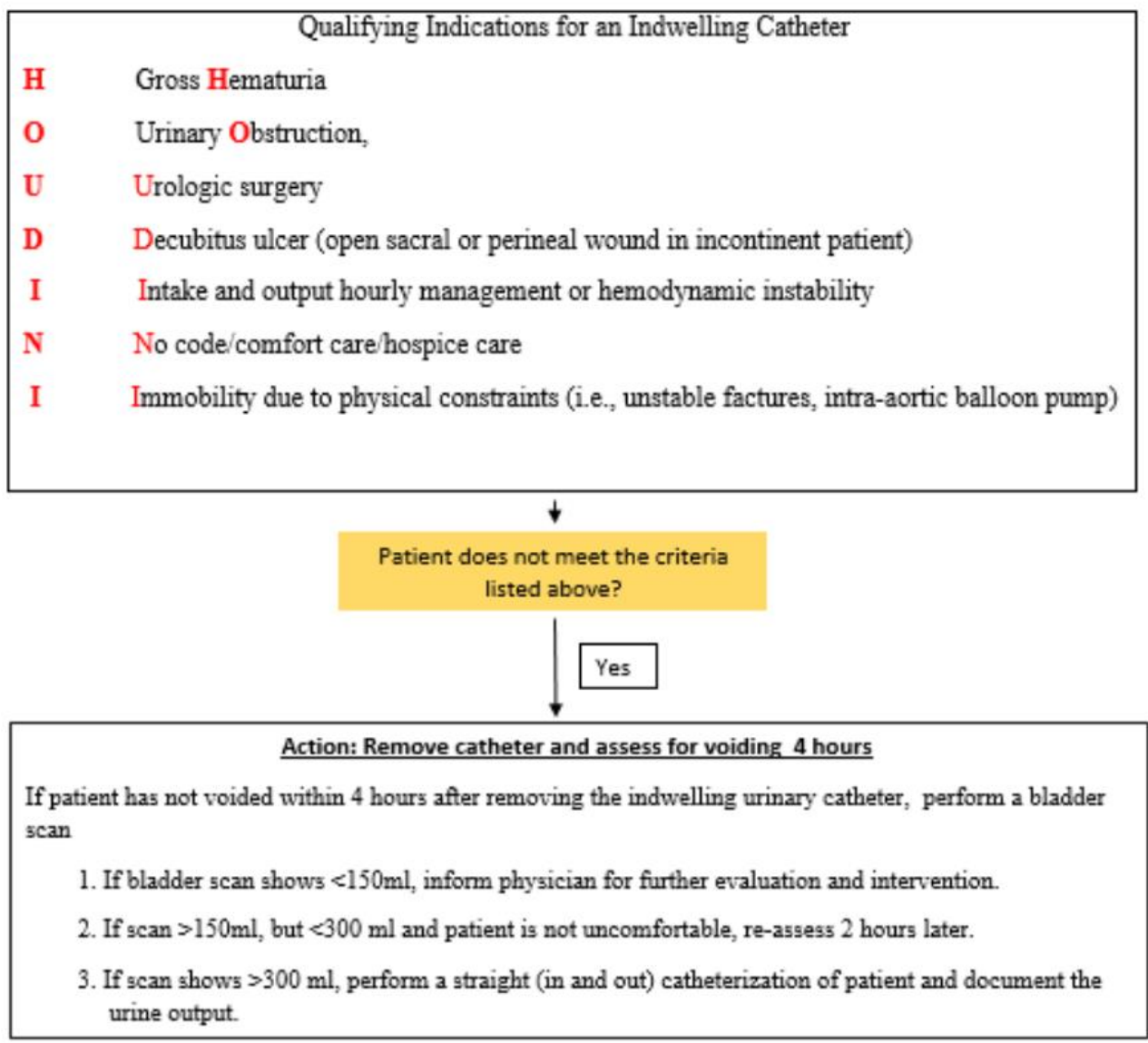

Adapted from BIC Healthcare Leaders (BIC, 2013). https://www. advisary.com/research/nursing-executivecenter/expert- 


\section{Appendix F}

\section{Urinary Catheter Removal Assessment Tool}

\section{Urinary Catheter Removal Assessment Tool}

Directions:

1. To complete the form, assess each qualifying criteria as indicated below.

2. If the result of your assessment indicate Yes on any areas do not discontinue the indwelling urinary catheter and consult physician for further evaluation and intervention.

3. When the patient meets the criteria for discontinuation of the indwelling urinary catheter, refer to the actions below.

4. Once the form is completed|file it into the patient's medical record.

Patient's Identifier Number:

Patient's Diagnosis:

Date

Age:

18- 25 years

25-35 years

$35-45$ years

Above 45 years

Gender:

Male $\square$ Female Qualifying Indications for an Indwelling Catheter

\begin{tabular}{|c|l|l|l|}
\hline \multicolumn{2}{|c|}{ Qualifying Indications for an Indwelling Catheter } & Yes & No \\
\hline H & gross hematuria & & \\
\hline O & urinary obstruction & & \\
\hline U & urologic surgery & & \\
\hline D & decubitus ulcer (open sacral or perineal wound on an incontinent patient) & & \\
\hline I & intake and output hourly management or hemodynamic instability & & \\
\hline N & no code/comfort care/hospice care & & \\
\hline I & $\begin{array}{l}\text { immobility due to physical constraints (i.e., unstable fractures, intra-aortic } \\
\text { balloon pump) }\end{array}$ & & \\
\hline \hline
\end{tabular}

\section{Action: Remove catheter and assess for voiding 4 hours}

If patient has not voided within 4 hours after removing the indwelling urinary catheter, perform a bladder scan

1. If bladder scan shows $<150 \mathrm{ml}$, inform physician for further evaluation and intervention.

2. If scan $>150 \mathrm{ml}$, but $<300 \mathrm{ml}$ and patient is not uncomfortable, re-assess 2 hours later.

3. If scan shows $>300 \mathrm{ml}$, perform a straight (in and out) catheterization of patient and document the urine

Time removal of catheter:

Time of Initial Void:

RN Name :

Date/Time 


\section{Appendix G}

\section{Indwelling Urinary Catheter Removal HOUDINI Nurse-Driven Protocol Lesson Plan}

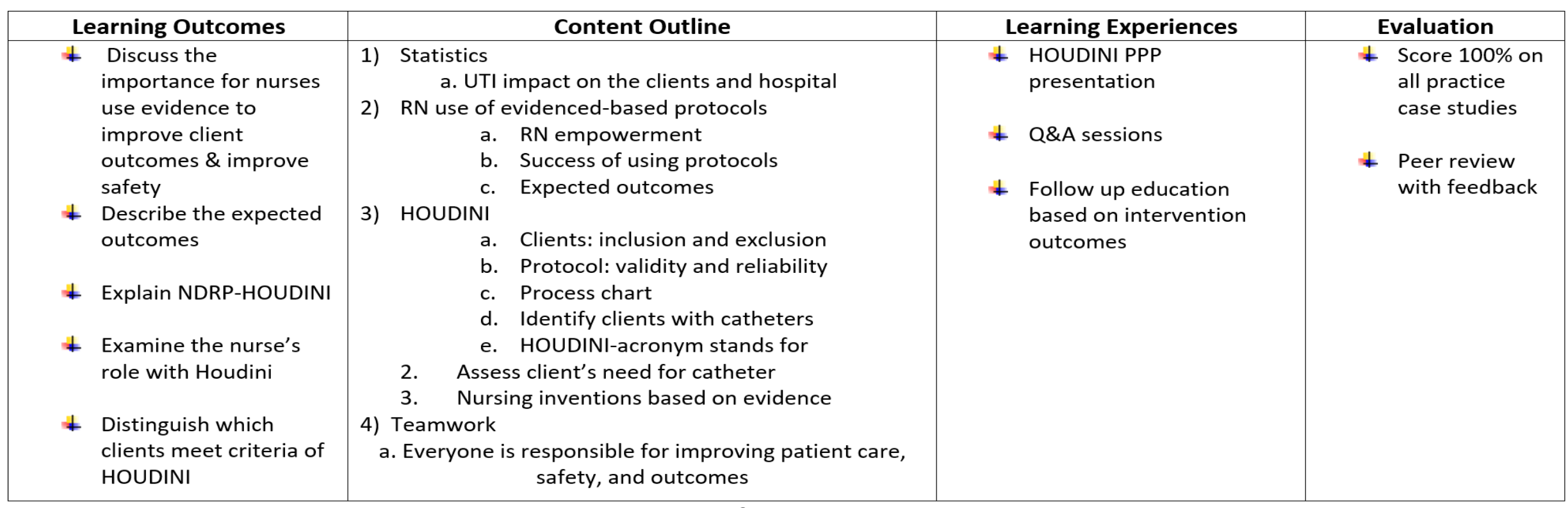

References

BJC Healthcare (2013). https://www.advisory.com/-/media/Advisory-com/Research/NEC/Events/Webconference/2013/Expanding-Nurse-Clinical-Decision-Making-Urinary-CatheterRemoval.pdf

Cardenas, D. D., Hoffman, J. M., Kirshblum, S., \& McKinley, W. (2004). Etiology and incidence of rehospitalization after traumatic spinal cord injury: A multicenter analysis. Archives of Physical Medicine and Rehabilitation, 85(11), 1757-1763. https://doi.org/10.1016/j.apmr.2004.03.016

Centers for Disease Control and Prevention. (2015). Catheter-associated urinary infections (CAUTIs). https://www.cdc.gov/hai/ca uti/uti.html

Gesmundo, M. (2016). Enhancing nurses' knowledge on catheter-associated urinary tract infection (Cauti) prevention. Kai Tiaki Nursing Research, 7(1),

32-40. http://search.ebscohost.com/login.aspx?direct=true\&db=ccm\&AN=119345448\&site=eds-live.

Mori, C, (2014). A voiding catastrophe. Implementing a nurse driven protocol. MedSurg Nursing 23(1), 15-28.

http://search.ebscohost.com/login.aspx?direct=true\&db=ccm\&AN=107891839\&site=eds-live 


\section{Appendix $\mathbf{H}$}

\section{Indwelling Urinary Catheter Removal HOUDINI Validation Assessment}

Indwelling Urinary Catheter Removal-HOUDINI Nurse-Driven Protocol Validation Assessment

\section{Post-Training Competency Validation for Unit Champions}

This goal of the project "Indwelling Urinary Catheter Removal- HOUDINI nurse-driven protocol" is to offer an evidence-based change practice which enhances patient outcomes by managing neurogenic bladder of a SCl patient. Please take a moment to answer the questions below. I thank you for your participation.

Staff Name:

$$
\text { Date: }
$$
Score:

1. Some ways to prevent CAUTI are through immediate removal of the catheter and or unnecessary catheterization.

$$
\begin{aligned}
& \text { a. True } \\
& \text { b. False }
\end{aligned}
$$

2. The nurse should assess the patient every shift to determine if the patient meets the criteria to leave the urinary catheter in place.

$$
\begin{aligned}
& \text { a. True } \\
& \text { b. False }
\end{aligned}
$$

3. The indications to leave indwelling urinary catheter in place include the following:
a. Gross Hematuria
c. Urologic surgery
c. Decubitus ulcer on sacral or perineal wound in incontinent patient
e. All the above

4. The nurse should evaluate the patient for voiding within 4 hours after catheter removal.

$$
\begin{array}{ll}
\text { a. True } \\
\text { b. False }
\end{array}
$$

5. Perform a bladder scan if the patient has not voided within 4 hours of catheter removal.

$$
\begin{aligned}
& \text { a. True } \\
& \text { b. False }
\end{aligned}
$$

\section{Post-Training Competency Validation Answer Key}

1. Some ways to prevent CAUTI are through immediate removal of the catheter and or unnecessary catheterization.
c. True

2. The nurse should assess the patient every shift to determine if the patient meets the criteria to leave the urinary catheter in place.

$$
\text { c. True }
$$

3. The indications to leave indwelling urinary catheter in place include the following:
f. Gross Hematuria
g. Urinary Obstruction
h. Urologic surgery
i. Decubitus ulcer on sacral or perineal wound in incontinent patien

j. All the above

4. The nurse should evaluate the patient for voiding within 4 hours after catheter removal.

c. True

5. Perform a bladder scan if the patient has not voided within 4 hours of catheter removal.

c. True 


\section{Appendix I}

In-service Flyer

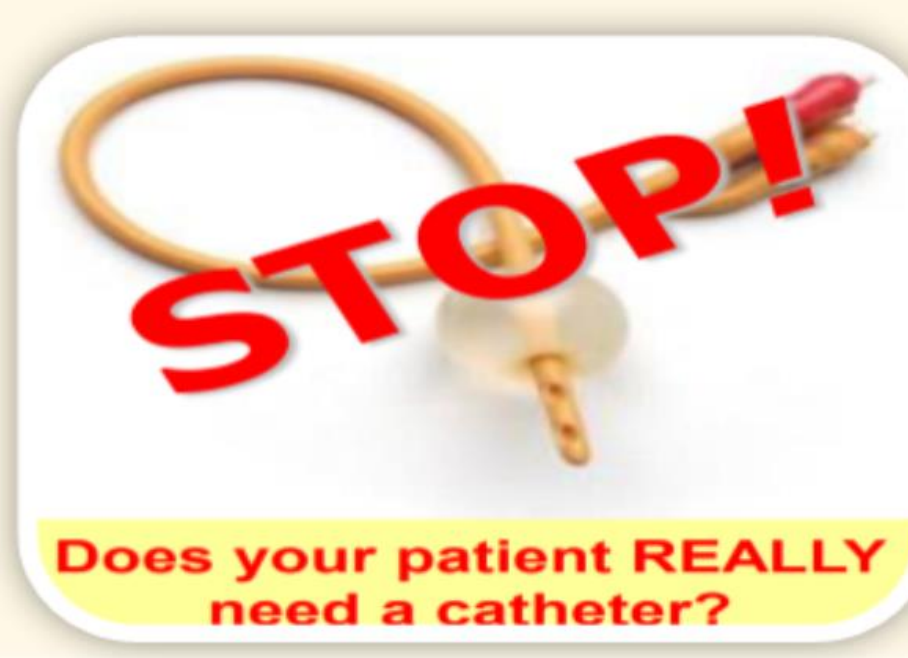

This in-service will examine the elements of Nurse Driven Removal Protocol process and facilitate the prompt discontinuation of urinary catheters Date: TBD

Time: $0730-0830$ \& | $400-1500$ Unit I South Activity Dining Room

Presented by: Fatima Villacruz, MBA, MSN

For any questions, please contact Fatima Villacruz @ext6232 or@f.villacruz@usa.edu 


\section{Appendix J}

\section{PowerPoint Presentation}
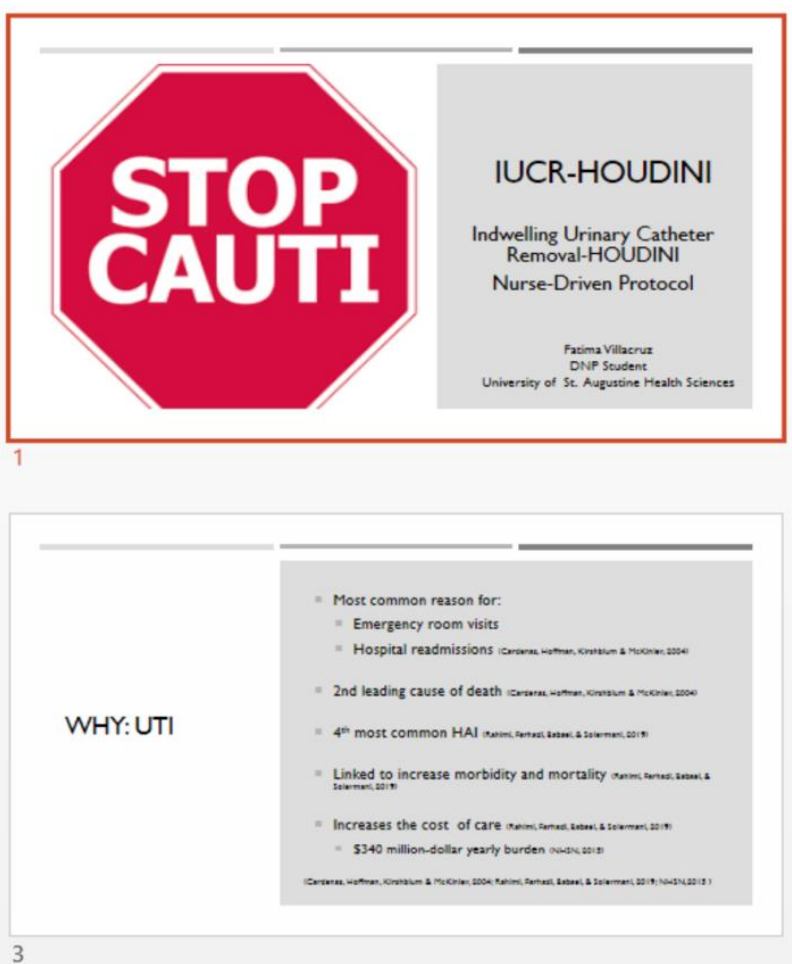

3

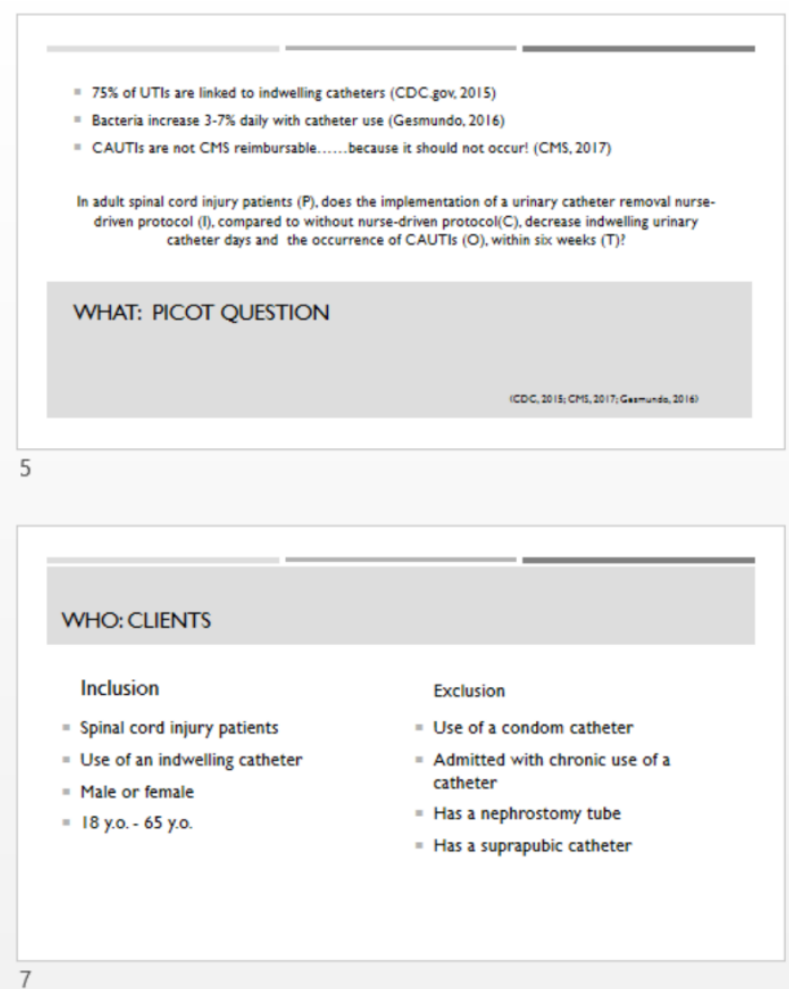

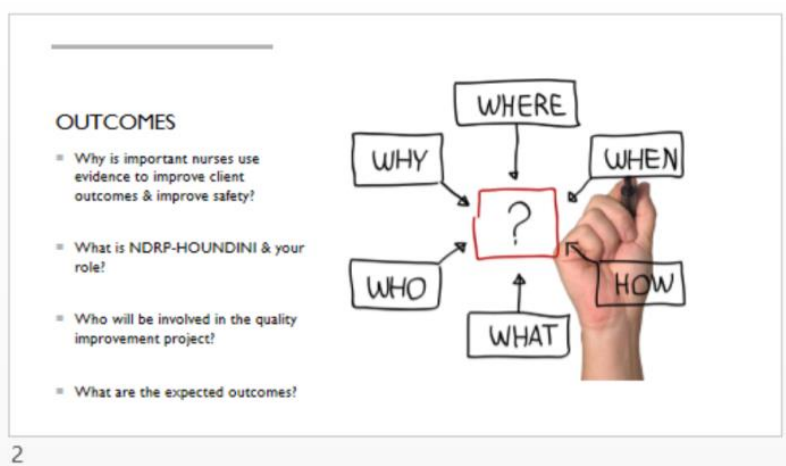

2

WHY: RN EMPOWERMENT!

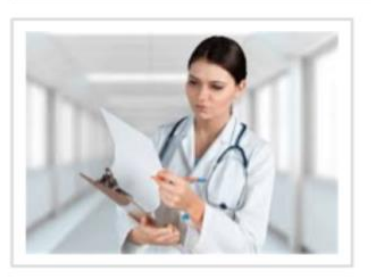

IMPLEMENT AN INDWELLING URINARY CATHETER REMOVAL [IUCR]HOUDINI NURSE-DRIVEN PROTOCOL

- Empower nurses!

- Provide evidence-based protocol driven by specific indications and diagnosis

Permits AUTONOMOUSLY catheter
removal

4

Reduce indwelling catheter use

- $37.6 \%$ to $27.7 \%$

Reduce indwelling catheter time

- 1,280-days preintervention to 1,025-days postintervention

NURSE-DRIVEN PROTOCOL STATISTICS

Reduction in CAUTIS

$0.77 \%$ to $0.35 \%$

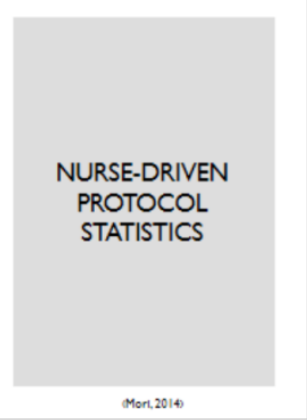

IUCR-HOUDINI

- Reliable and valid

- Exhibits decrease in catheter use and reduction in CATUI

- Promotes independent nursing practice

- Promotes collaborative practice 

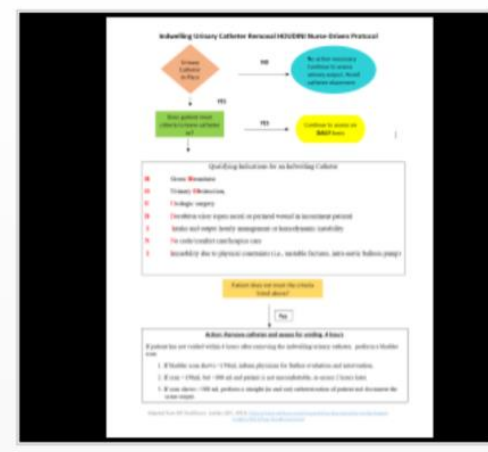

9

IUCR-HOUDINI:

FOLLOW PROTOCOL UNLESS ONE OF THESE FIT THE CLIENT

\section{HOUDINI:}

$\llcorner\mathrm{H}$ gross hematuria

ii. Obstruction, urinary

iii. Urologic surgery

iv. Decubitus ulcer (open sacral or perineal wound in incontinent patient)

v. Intake and output hourly management or hemodynamic instability

vi. No code/comfort care/hospice care

vii. Immobility due to physical constraints (i.e., unstable factures, intra-sortic balloon pump)

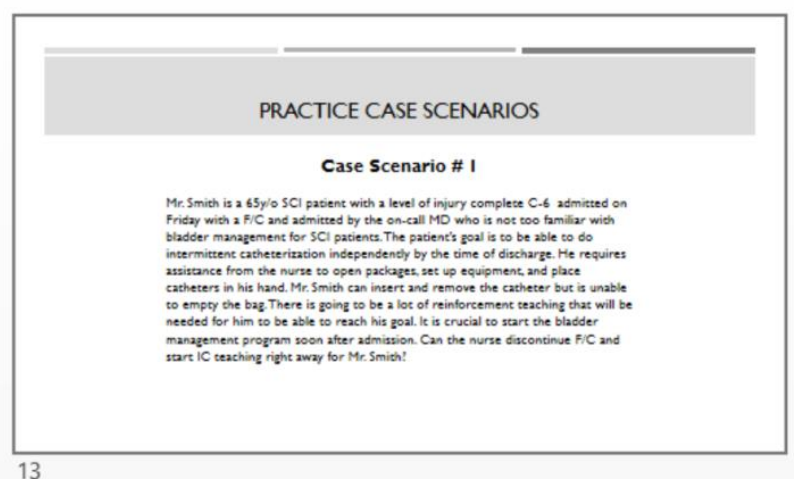

13

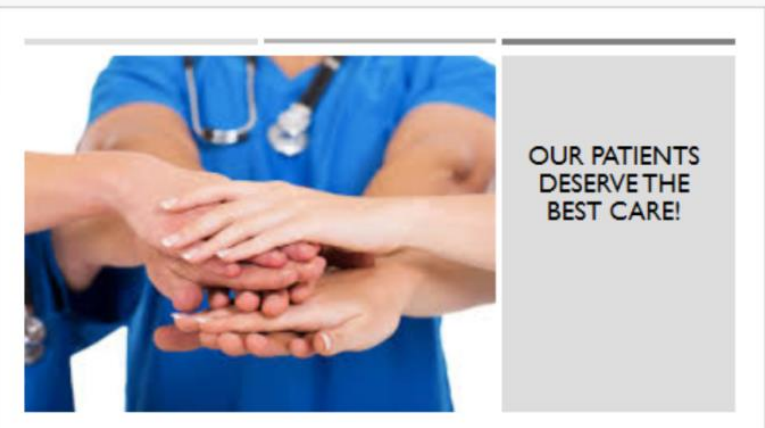

15

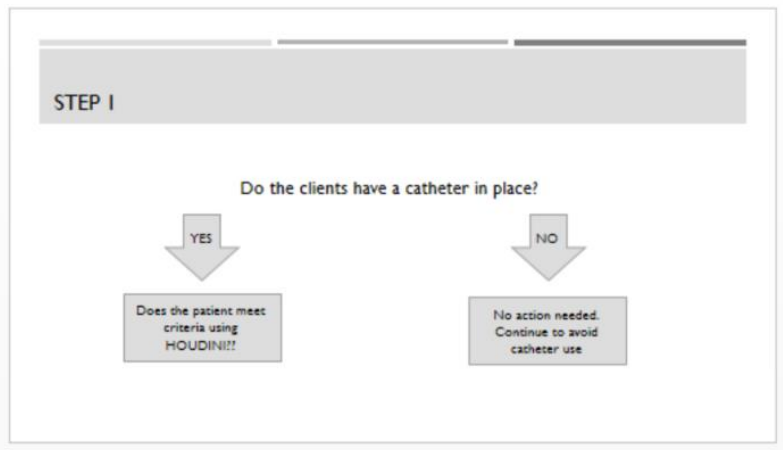

10
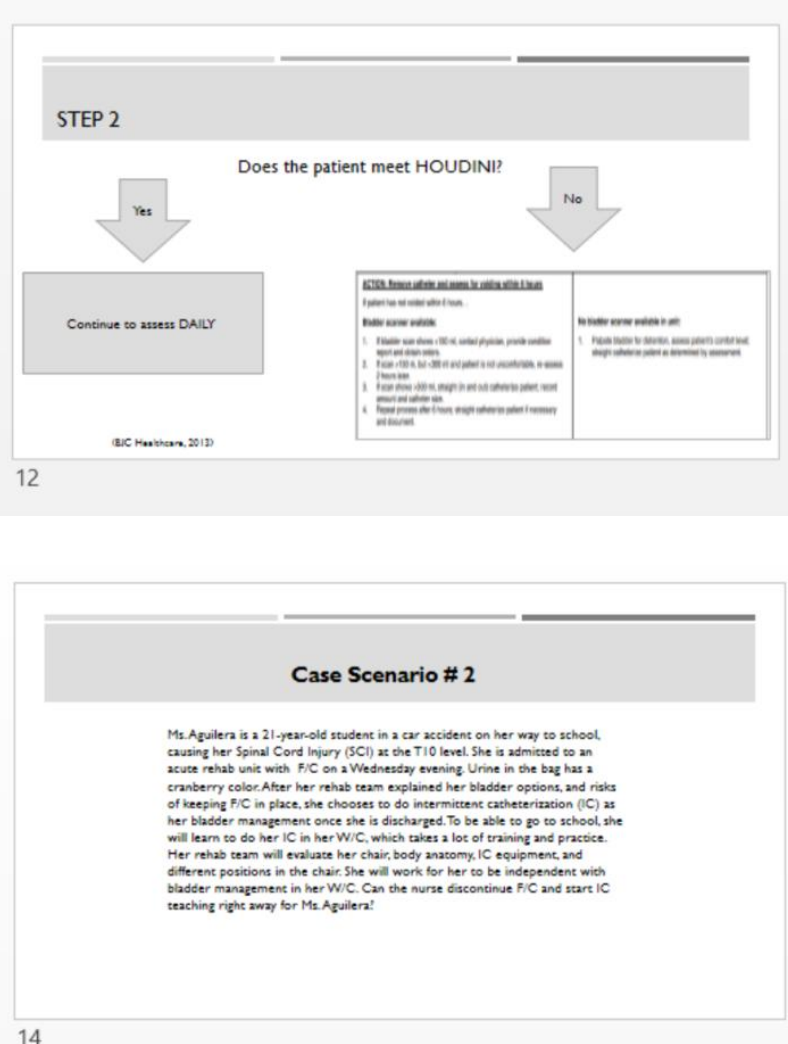

14

\section{REFERENCES}

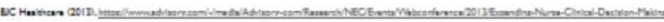

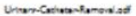

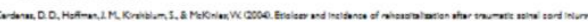

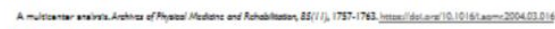

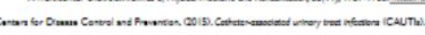

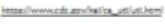

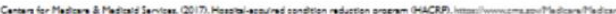



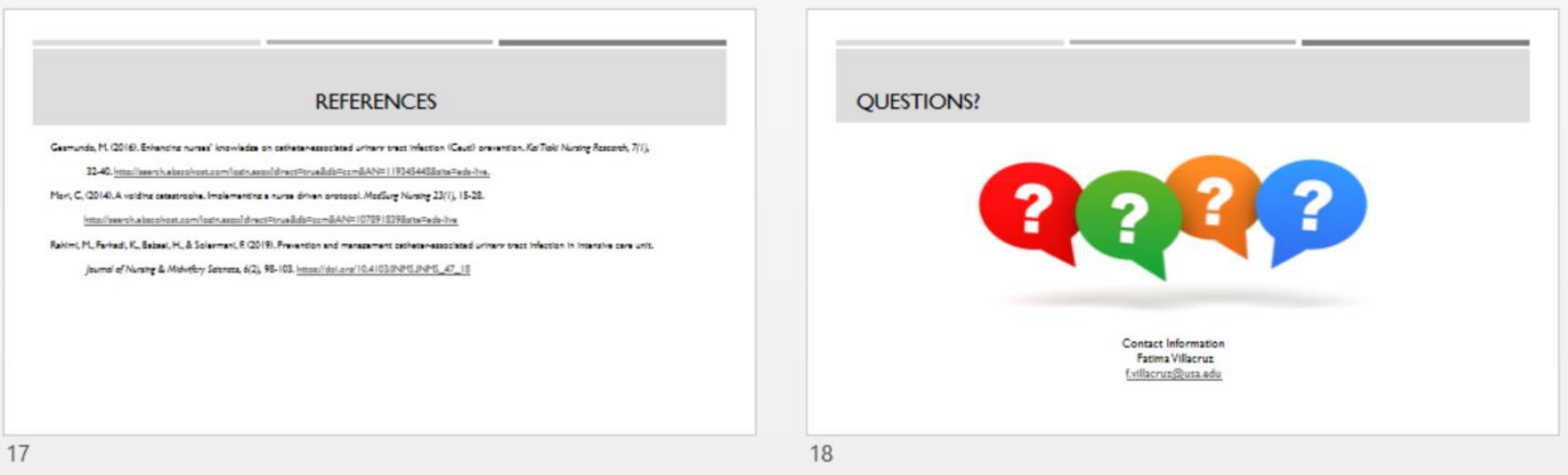


\section{Appendix K}

\section{Case Scenario}

After reviewing each scenario, utilize the provided "Catheter Removal Assessment Tool" to determine the appropriate clinical decision of removing indwelling urinary catheter according to the Indwelling Urinary

\section{Catheter Removal HOUDINI nurse-driven protocol.}

1. Smith is a $65 y / 0 \mathrm{SCl}$ patient with a level of injury complete $\mathrm{C}-6$ admitted on Friday with a F/C and admitted by the on-call MD who is not too familiar with bladder management for SCl patients. The patient's goal is to be able to do intermittent catheterization independently by the time of discharge. He requires assistance from the nurse to open packages, set up equipment, and place catheters in his hand. Mr. Smith can insert and remove the catheter but is unable to empty the bag. There is going to be a lot of reinforcement teaching that will be needed for him to be able to reach his goal. It is crucial to start the bladder management program soon after admission. Can the nurse discontinue F/C and start IC teaching right away for Mr. Smith?

\section{Answer Yes or No}

2. Ms. Aguilera is a 21-year-old student in a car accident on her way to school, causing her Spinal Cord Injury $(\mathrm{SCl})$ at the T10 level. She is admitted to an acute rehab unit with $\mathrm{F} / \mathrm{C}$ on a Wednesday evening. Urine in the bag has a cranberry color. After her rehab team explained her bladder options, and risks of keeping F/C in place, she chooses to do intermittent catheterization (IC) as her bladder management once she is discharged. To be able to go to school, she will learn to do her IC in her W/C, which takes a lot of training and practice. Her rehab team will evaluate her chair, body anatomy, IC equipment, and different positions in the chair. She will work for her to be independent with bladder management in her W/C. Can the nurse discontinue F/C and start IC teaching right away for Ms. Aguilera?

\section{Answer Yes or No}




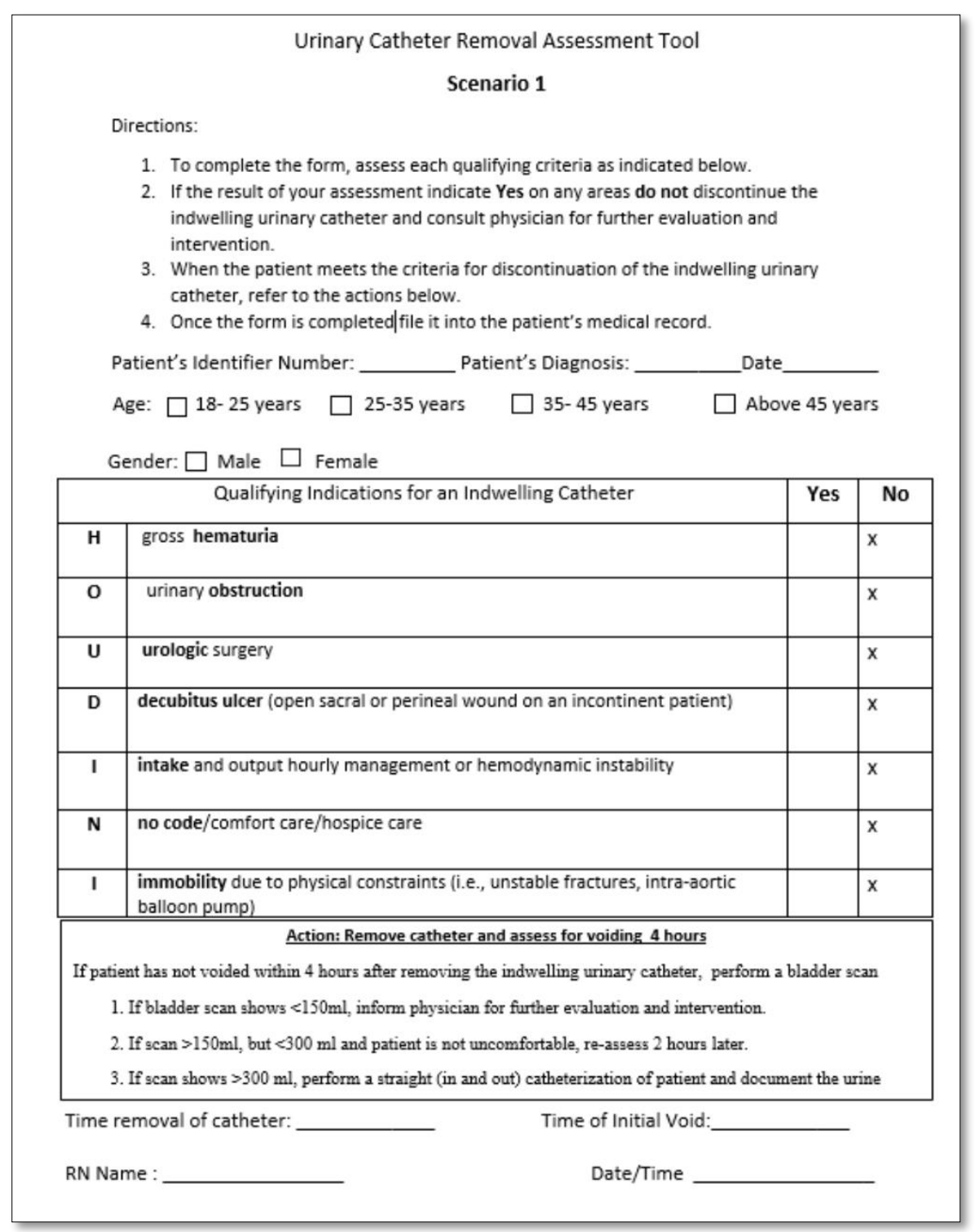

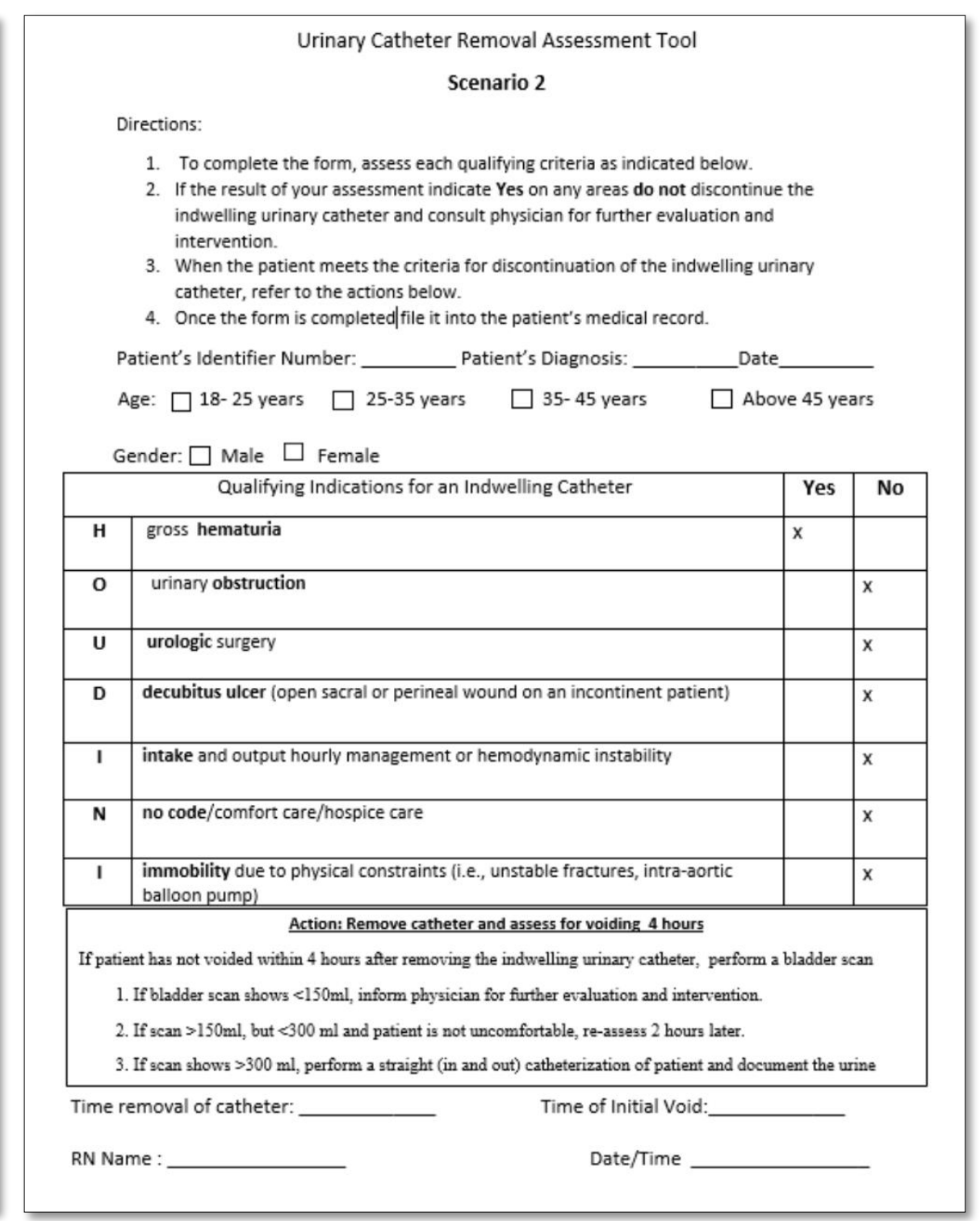


Appendix L

In-service Rosters

\section{Indwelling Urinary Catheter Removal "HOUDINI" Nurse- Driven Protocol In-service}

\begin{tabular}{|c|c|c|c|}
\hline Date & PRINT NAME/Title & Shift & $\begin{array}{c}\text { Employee } \\
\text { Number }\end{array}$ \\
\hline & & & \\
\hline & & & \\
\hline & & & \\
\hline & & & \\
\hline & & & \\
\hline & & & \\
\hline & & & \\
\hline & & & \\
\hline & & & \\
\hline & & & \\
\hline & & & \\
\hline & & & \\
\hline & & & \\
\hline & & & \\
\hline & & & \\
\hline & & & \\
\hline & & & \\
\hline
\end{tabular}




\section{Appendix M}

Catheter Removal Audit Tool

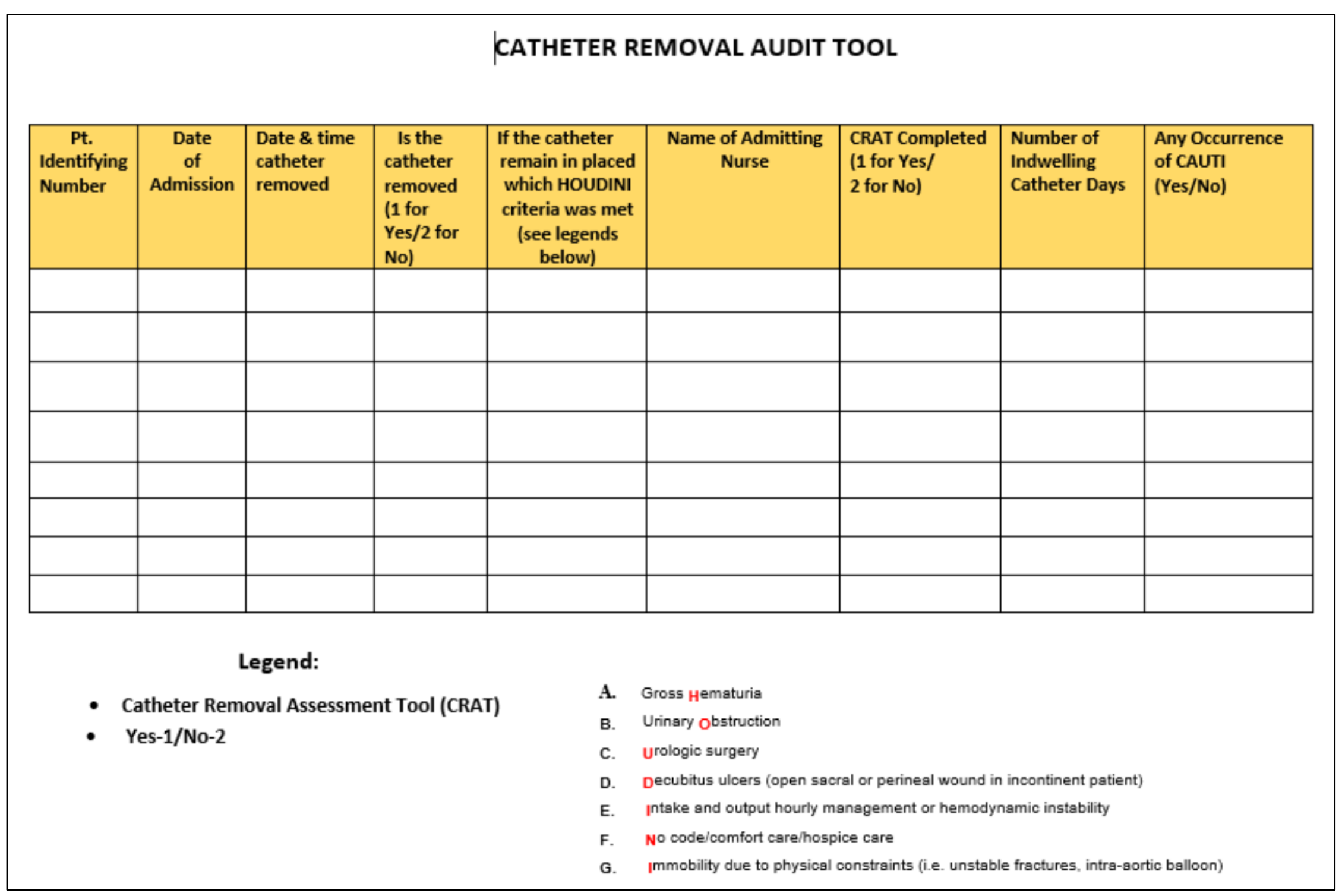




\section{Appendix N}

\section{Gantt Chart}

\begin{tabular}{|c|c|c|c|c|}
\hline 4 & A & $\mathrm{B}$ & $\mathrm{C}$ & $\mathrm{D}$ \\
\hline 1 & \multirow{3}{*}{\multicolumn{2}{|c|}{$\begin{array}{l}\text { Implementation of Indwellimg Urinary Catheter Removal HOUDINI Nurse-Driven Protocol } \\
\text { Fatima Villacruz - Project Manager }\end{array}$}} & \multicolumn{2}{|c|}{ Mon, 5/11/2020 } \\
\hline 2 & & & \multicolumn{2}{|c|}{ Tue, $1 / 5 / 2021$} \\
\hline 3 & & & 1 & \\
\hline 4 & & & & \\
\hline 5 & TASK & $\begin{array}{c}\text { ASSIGNED } \\
\text { TO }\end{array}$ & START & END \\
\hline 6 & Phase 1: Planning & \multirow{9}{*}{$\begin{array}{l}\text { Fatima Villacruz, Project } \\
\text { Manager }\end{array}$} & & \\
\hline 7 & Meeting with CNO, Michelle Sterling for support on the identified project & & 11-May & 11-May \\
\hline 8 & Generate a title for the project & & 12-May & 13-May \\
\hline 9 & Perform a literature review to support the problem, centering on CAUTIs & & 14-May & 16-May \\
\hline 10 & Perform additional literature review to discover the available knowledge & & 17-May & 19-May \\
\hline 11 & $\begin{array}{l}\text { Evaluate and learn which approved standard method and educational } \\
\text { material to do }\end{array}$ & & 20-May & 24-May \\
\hline 12 & $\begin{array}{l}\text { Identify theories, explain the problem and the assumption that the } \\
\text { execution will work }\end{array}$ & & 25-May & 27-May \\
\hline \multirow[t]{2}{*}{13} & Complete the specific aim with a precise, objective measure & & 28-May & 29-May \\
\hline & $\begin{array}{l}\text { Meet with Dr. Joseph Tadeo, Nursing Director, Utilization Management, my } \\
\text { preceptor to review the available data and the key stakeholders that will } \\
\text { be on board with the project }\end{array}$ & & 1-Jun & 1-Jun \\
\hline 15 & \multicolumn{4}{|l|}{ Collection of Internal Data } \\
\hline 16 & $\begin{array}{l}\text { Gather data about average catheter days, rate of CAUTI rate and } \\
\text { aveage number of SCl patient admitted with foley catheter }\end{array}$ & $\begin{array}{l}\text { Fatima Villacruz, Project } \\
\text { Manager }\end{array}$ & 25-May & 1-Jun \\
\hline \multirow[t]{2}{*}{17} & $\begin{array}{l}\text { Complete the SWOT analysiis with the key } \\
\text { stakeholders }\end{array}$ & $\begin{array}{l}\text { Fatima Villacruz, Project } \\
\text { Manager }\end{array}$ & 2-Jun & 4-Jun \\
\hline & Complete the Checklist to Assess Organizational Readiness (CARI) & Michelle Streling, CNO & 5-Jun & 5-Jun \\
\hline 19 & Obtain a budget and a job description for a unit champion & Deepa Kannampuzha, NM & 8-Jun & 19-Jun \\
\hline \multirow[t]{2}{*}{20} & Indwelling Urinay Catheter Removal -HOUDINI Protocol Education & & & \\
\hline & $\begin{array}{l}\text { Design nursing education: Established process for applying the new } \\
\text { nurse driven protocol for cathteter removal }\end{array}$ & $\begin{array}{l}\text { Veronica Terrogoza Unit } \\
\text { Educator, Project Manager }\end{array}$ & 8-Jun & 19-Jun \\
\hline 22 & $\begin{array}{l}\text { Analysis and gather possible explication for difficulties using nurse } \\
\text { driven protocol for cathteter removal }\end{array}$ & Fatima Villacruz, Project Lead & 8-Jun & 19-Jun \\
\hline
\end{tabular}




\begin{tabular}{|c|c|c|c|c|}
\hline 23 & $\begin{array}{l}\text { Outline specific education on new nurse driven protocol: benefits } \\
\text { and patient education for patients }\end{array}$ & $\begin{array}{l}\text { Fatima Villacruz, Project } \\
\text { Lead }\end{array}$ & 8-Jun & 19-Jun \\
\hline 24 & Intervention Planning & & & \\
\hline 25 & $\begin{array}{l}\text { Recommended by current evidence build a well-organized } \\
\text { process with key stakeholders to reduce the CAUTI rate and } \\
\text { catheter use with SCl patient }\end{array}$ & $\begin{array}{l}\text { Fatima Villacruz, Project } \\
\text { Manager }\end{array}$ & 22-Jun & 5-Jul \\
\hline 26 & $\begin{array}{l}\text { Set guidelines for admitting a patient to include new driven } \\
\text { protocol discussion }\end{array}$ & hit ChampionsiProject Manag & 22-Jun & 1-Jul \\
\hline 27 & Formulate a checklist of the process & $\begin{array}{l}\text { Fatima Villacruz, Project } \\
\text { Manager }\end{array}$ & $6-J u l$ & 8-Jul \\
\hline 28 & Measures \& Examination & & & \\
\hline 29 & Possible ethical concerns and how to address when recognize & \multirow{5}{*}{$\begin{array}{l}\text { Fatima Villacruz, Project } \\
\text { ManageriUnit Champions }\end{array}$} & $6-J u l$ & 13-Jul \\
\hline 30 & $\begin{array}{l}\text { Define the outcome measurements and validitylreliability for each } \\
\text { measure }\end{array}$ & & 14-Jul & 18-Jul \\
\hline 31 & Monitor each intervention for accuracy and completion & & 19-Jul & 24-Jul \\
\hline 32 & Discover quantitative approaches for each method & & 25-Jul & 29-Jul \\
\hline 33 & Determine methods to comprehend variation within the data & & $30-J u l$ & 3-Aug \\
\hline 34 & \multicolumn{4}{|l|}{ Project Approval } \\
\hline 35 & Gain approval from Univrsity of St. Augustine Health Services & $\begin{array}{c}\text { Fatima Villacruz, Project } \\
\text { Manager }\end{array}$ & $17-\square c t$ & $19-\square c t$ \\
\hline 36 & Approval from Evidence-Based Practice Council (facility project s & $\begin{array}{l}\text { Fatima Villacruz, Project } \\
\text { Manager }\end{array}$ & $20-0 \mathrm{ct}$ & 22-Dot \\
\hline 37 & Final approval from Nurse Executive Council (facility project site) & $\begin{array}{l}\text { Fatima Villacruz, Project } \\
\text { Manager }\end{array}$ & 23-0et & $25-0 \mathrm{ct}$ \\
\hline 38 & Phase 2: Implementation & & & \\
\hline 39 & stakeholders and intedisxciplinary team nitification of of the project app & $\begin{array}{c}\text { Fatima Villacruz, Project } \\
\text { Manager }\end{array}$ & 26-Det & 27-Dot \\
\hline 40 & Staff education on Indw elling Urinary Catheter Removal Protocol HC & $\begin{array}{l}\text { Veronica Torregoza Unit } \\
\text { Educator IProject Manager }\end{array}$ & 27-Det & 30-Dot \\
\hline 41 & Identify the completion rate of education from stakeholders & $\begin{array}{l}\text { Fatima Villacruz, Project } \\
\text { Manager }\end{array}$ & 30-Det & 30-Dot \\
\hline 42 & Project Implementation & & & \\
\hline 43 & $\begin{array}{l}\text { SCIUnit Project Implementation of Indw elling Urinary Catheter } \\
\text { Removal-HOUD|N/nurse-driven orotocol }\end{array}$ & SCIFrontine Staff & 1-Nov & 16-Dec \\
\hline 44 & Weekly monitoring of the nurse driven protocol initiatives & $\begin{array}{l}\text { Fatima Villacruz, Project } \\
\text { Manager }\end{array}$ & 9-Nov & $16-$-Deo \\
\hline 45 & Data collection daily and identified barriers and solutions & $\begin{array}{l}\text { Fatima Villacruz, Project } \\
\text { Manager }\end{array}$ & 1-Nov & 16 -Dec \\
\hline 46 & $\begin{aligned} & \text { Phase 3: Evaluation } \\
&\end{aligned}$ & & & \\
\hline 47 & \multicolumn{2}{|l|}{ Analyze and evaluate all collected data from Indwelling Urinary Cathe:er } & 17-Dec & 30-Dec \\
\hline 48 & Removal HOUDIN nurse-driven protocol project & & & \\
\hline 49 & & & & \\
\hline 50 & \multicolumn{2}{|c|}{ Celerate success and disseminate outcome with the interdiscoipinary team and other involved stah } & 31-Dec & 5-Jan \\
\hline 51 & & & & \\
\hline
\end{tabular}




\section{Appendix 0}

\section{Estimated Cost of the Project Implementation}

\begin{tabular}{|l|c|c|}
\hline SCI Project Team Participants & Hourly & Total Cost \\
\hline Thirty-three SCI RNs & $\$ 45.00$ & 148.00 \\
\hline Unit Champions (Certified Rehabilitation Nurse CCRNs) x2 & 55.00 & 330.00 \\
\hline Infection Control and Preventionist Nurse & 55.00 & 0.00 \\
\hline Unit Manager & Salary & 204.00 \\
\hline Unit Clinical Educator & 68.00 & 600.00 \\
\hline Rehab providers (total x 2) & 150.00 & 170.00 \\
\hline Rehabilitation Clinical Nurse Specialist & 85.00 & 400.00 \\
\hline Other & & 50.00 \\
\hline Materials for implementation (poster board, tapes, stock papers) & & $3,404.00$ \\
\hline Total Operating Expenses & & \\
\hline
\end{tabular}




\section{Appendix P}

\section{Permission awarded email of using 'HOUDINI Protocol'}

Vonderhaar, Katherine $Y<$ Vonderhk@advisory.com>

Mon 9/21/2020 2:01 PM

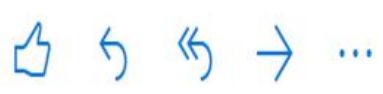

To: Fatima Villacruz

Cc: Sue Ellen Bingham

Expanding-Nurse-Clinical-De...

回 353 KB

$\bigvee$ Show all 3 attachments (1 MB) Download all Save all to OneDrive - University of St Augustine

Hi Fatima,

It's nice to meet you!

Nursing leaders at BIC HealthCare graciously shared the HOUDINI protocol and talking points with Advisory Board members. I've attached those, along with our write-up of the protocol as a best practice (excerpted from our 2013 report Achieving Top-of-License Nursing Practice).

You are welcome to use these materials; please be sure to credit BJC HealthCare appropriately for the protocol and talking points (and Advisory Board, if you use any of the insight from the best practice report).

I hope this helps! Best of luck with your studies.

Take care, Kate
Expanding-Nurse-Clinical-De...

419 KB 